\title{
ACTRIS ACSM intercomparison - Part 2: Intercomparison of ME-2 or- ganic source apportionment results from 15 individual, co-located aerosol mass spectrometers
}

\section{R. Fröhlich et al.}

Correspondence to: A. S. H. Prévôt (andre.prevot@psi.ch)

The copyright of individual parts of the supplement might differ from the CC-BY 3.0 licence. 
1 Supplementary figures, tables and equations

$z$-score:

$z=\frac{\left(x_{i, j}-X_{j}\right)}{\sigma_{j}}$

with $x_{i, j}$ : contribution of source $j$ for instrument $i$

$X_{j}$ : median contribution of source $\mathrm{j}$

$\sigma_{j}$ : standard deviation 
Tab. S 1. Participating ACSM instruments sorted by serial number. The order of instruments in this table purposely does not coincide with the order \#1 - \#13 used in the text to avoid an unintentional "rating" of individual instruments.

\begin{tabular}{llll}
\hline ACSM serial \# & Operating institution(s) & Country & $\begin{array}{l}\text { Monitoring location } \\
\text { ACTRIS }\end{array}$ \\
\hline d $140-104$ & University of Helsinki & Finland \\
A140-110 & IDAEA-CSIC & Spain & Hyytiälä, FIN \\
A140-113 & LSCE & France & Montseny, ESP \\
A140-133 & National University of Ireland, Galway & Ireland & Gif-Sur-Yvette (SIRTA), FRA \\
A140-134 & DWD & Germany & Mace Head, IRL \\
A140-142 & LSCE & France & Hohenpeißenberg, DEU \\
A140-143 & TROPOS & Germany & Cap Corse, FRA \\
A140-144 & NILU & Norway & Melpitz, DEU \\
A140-145 & PSI & Switzerland & Birkenes, NOR \\
A140-151 & EC-JRC \& ENEA & Italy \& Italy & Cabauw, NLD \\
A140-152 & ISAC-CNR & Italy & Ispra, ITA \\
A140-153 & CIEMAT & Spain & Bologna, ITA \\
A140-156 & King's College London & United Kingdom & Madrid, ESP \\
ToF A003 & PSI & Switzerland & North Kensington, GBR \\
HTOF AMS 215-081 & Ecole Nationale Supérieure des Mines & France & Jungfraujoch, CHE \\
& de Douai & & Revin, FRA (EMEP) \\
\hline
\end{tabular}

Tab. S 2. Calibrated values of the Q-ACSM response factor (ions / pg value for the ToF-ACSM).

\begin{tabular}{ll}
\hline ACSM serial \# & $\begin{array}{l}\text { Response factor }(\mathbf{R F}) \\
\text { in } \mathbf{A} /\left(\boldsymbol{\mu g} / \mathbf{m}^{3}\right)\end{array}$ \\
\hline A140-104 & $3.0 \times 10^{-11}$ \\
A140-110 & $5.3 \times 10^{-11}$ \\
A140-113 & $4.4 \times 10^{-11}$ \\
A140-133 & $4.0 \times 10^{-11}$ \\
A140-134 & $3.1 \times 10^{-11}$ \\
A140-142 & $3.7 \times 10^{-11}$ \\
A140-143 & $5.5 \times 10^{-11}$ \\
A140-144 & $2.8 \times 10^{-11}$ \\
A140-145 & $2.4 \times 10^{-11}$ \\
A140-151 & $3.0 \times 10^{-11}$ \\
A140-152 & $2.7 \times 10^{-11}$ \\
A140-153 & $3.1 \times 10^{-11}$ \\
A140-156 & $3.3 \times 10^{-11}$ \\
ToF A003 & 8.6 ions / pg \\
\hline
\end{tabular}


Tab. S 3. Modifications of calculated ME2 input matrices before analysis. $m / z 12$ was removed in all Q-ACSM instruments due to nonphysical negative signals.

\begin{tabular}{lll}
\hline Instrument & $\begin{array}{l}m / z \text { downweighted } \\
\text { by factor 3 }\end{array}$ & additional info \\
\hline ToF & none & \\
$\# 1$ & $m / z 13 \& 24$ & \\
$\# 2$ & $m / z 13 \& 15$ & \\
$\# 3$ & $m / z 13$ & \\
$\# 4$ & $m / z 13,15,24 \& 37$ & \\
$\# 5$ & none & \\
$\# 6$ & $m / z 15$ & \\
$\# 7$ & $m / z 13$ removed (neg. S/N) \\
$\# 8$ & $m / z 13,15, \& 37$ & \\
$\# 9$ & $m / z 13 \& 15$ & \\
$\# 10$ & $m / z 13 \& 15$ & \\
$\# 11$ & none & \\
$\# 12$ & none & \\
$\# 13$ & $m / z 13 \& 15$ & $7 \mathrm{entries} \mathrm{removed:}^{+}$ \\
$\mathrm{HR}-\mathrm{AMS}$ & $\mathrm{CH} \mathrm{H}_{2}^{+}(14.0156) \&$ & $\mathrm{CH}_{4}^{+}(16.0313)$, \\
& $\mathrm{C}_{3} \mathrm{H}_{3}^{+}(39.0235)$ by factor 3 & $\mathrm{CH}_{4} \mathrm{O}^{+}(32.0262)$, \\
& $\mathrm{CH} \mathrm{O}_{3}^{+}(62.9905)$ by factor 6 & $\mathrm{CH}_{2} \mathrm{O}_{2}^{+}(46.0055)$, \\
& & $\mathrm{CH}_{4} \mathrm{NO}^{+}(46.0293)$, \\
& & $\mathrm{C}_{2} \mathrm{H}_{6} \mathrm{O}^{+}(46.0419)$, \\
& & $\mathrm{C}_{2} \mathrm{HCl}_{2}^{+}(94.9455)$, \\
& & $\mathrm{C}_{3} \mathrm{H}_{3} \mathrm{O}_{5}^{+}(118.998)$ \\
\hline
\end{tabular}

Tab. S 4. Correlations $\left(\mathrm{R}^{2}\right)$ between factors from HR PMF analysis with external measurements.

\begin{tabular}{lllll}
\hline $\mathbf{R}^{2}$ & $\mathbf{B C}_{\mathbf{w b}}$ & $\mathbf{B C}_{\mathbf{f f}}$ & $\mathbf{N O}_{\mathbf{x}}$ & $\mathbf{S O}_{\mathbf{4}}$ \\
\hline$\# 1$ (HOA) & 0.39 & 0.68 & 0.65 & 0.02 \\
$\# 2$ (COA) & 0.64 & 0.40 & 0.29 & 0.15 \\
$\# 3$ (OOA) & 0.20 & 0.15 & 0.06 & 0.50 \\
$\# 4$ (BBOA) & 0.90 & 0.27 & 0.22 & 0.08 \\
\hline
\end{tabular}



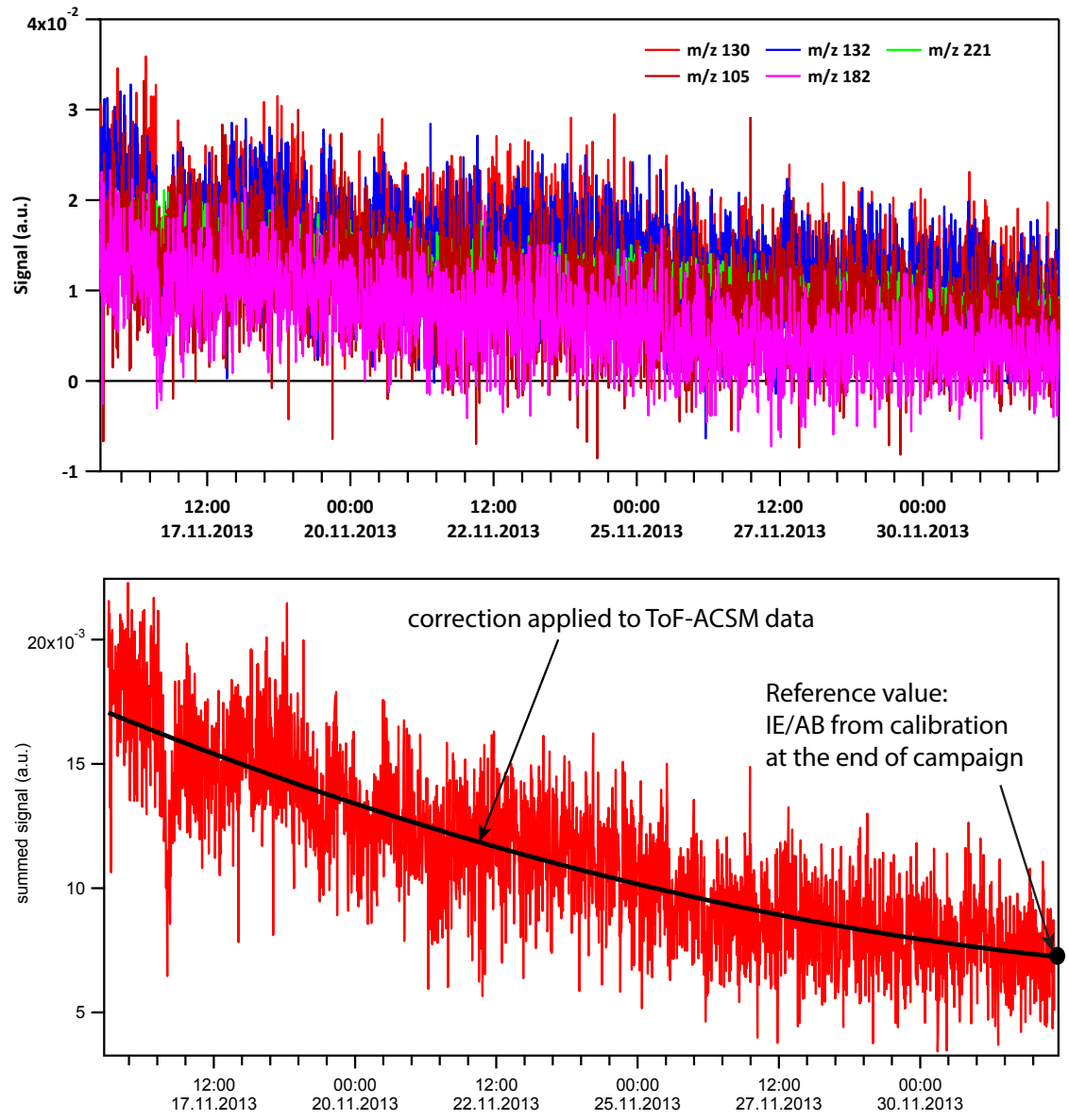

Fig. S 1. Top panel: signals of largest chamber background ions during the investigated period. All ions show a similar decrease, however concentrations of the chamber background ions are not expected to change over time (e.g. tungsten is released by the ioniser filament). Bottom panel: summed signal of all ions shown above. An exponential fit (black line) was calculated and used to correct the ambient data. The IE/AB value determined in a calibration after the campaign was used as reference. 

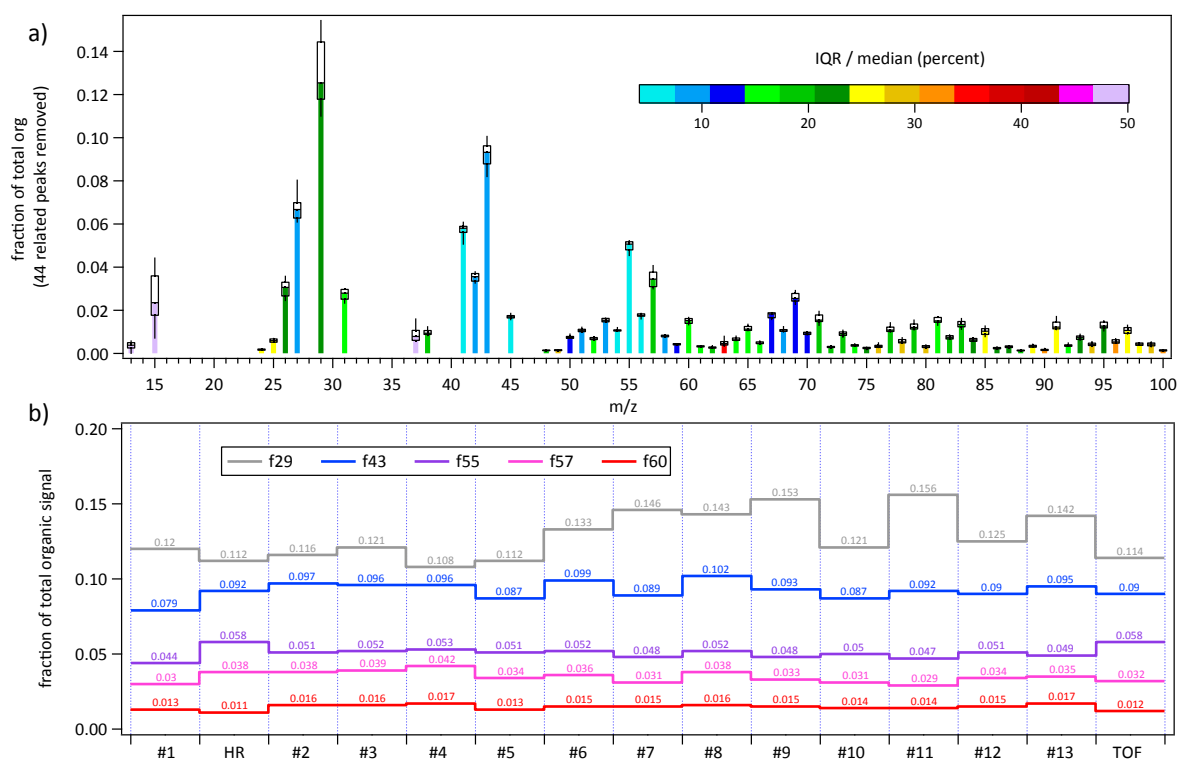

Fig. S 2. (a) Median organic mass spectrum of the 13 Q-ACSMs. The signals at $m / z=44$ and all related sticks $(m / z=16,17$ and 18$)$ were removed and the mass spectrum was then renormalised. The boxes represent the interquartile range (IQR) (25-75 percentile) for each $m / z$ stick and the whiskers represent the corresponding full range over all instruments. The colour bar represents the ratio of the width of the individual boxes in relation to the corresponding median in percent. (b) Fractions of the total organic signal at single $m / z$ channels for all 15 participating instruments after all $\mathrm{CO}_{2}^{+}$related peaks were removed from the spectrum. The instruments were sorted like in Fig. $2 \mathrm{a}$ (by fraction of $m / z 44$ before removing). Grey: f29, blue: $\mathrm{f} 43$, purple: $\mathrm{f} 55$, pink: $\mathrm{f} 57$, red: f60. The respective fractions are given as numbers in the same colours.

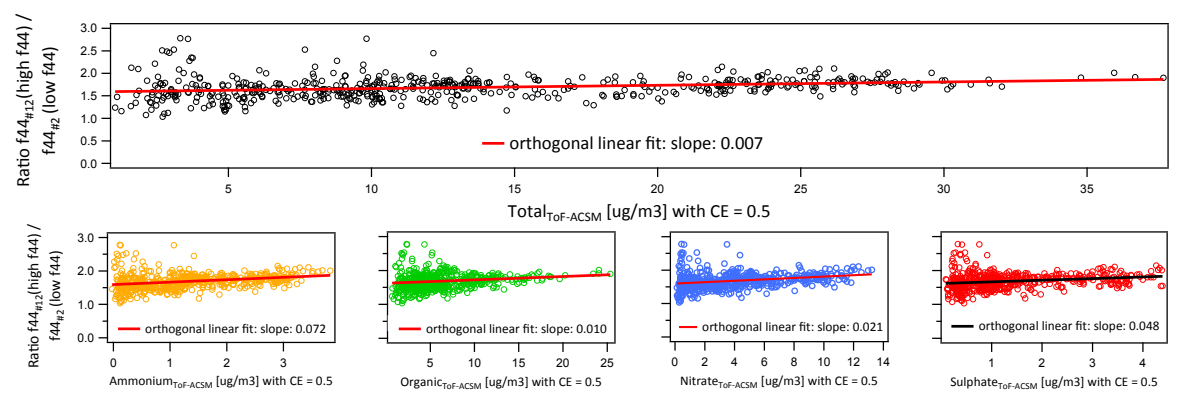

Fig. S 3. Ratio of $\mathrm{f} 44$ between a Q-ACSM with high $\mathrm{f} 44$ (\#12) and a Q-ACSM with low f44 (\#2, cf. Fig. 2b) plotted against concentration (black: total, yellow: ammonium, green: organics, blue: nitrate, red: sulphate). Slopes of an orthogonal linear regression are given in each plot. Slopes are all positive but very small, indicating only a very minor dependency of $\mathrm{f} 44$ on concentration. 
a)

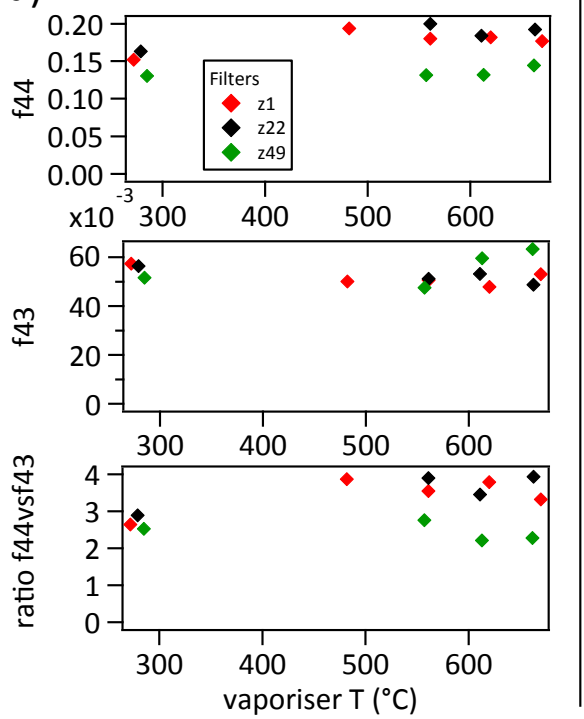

b)
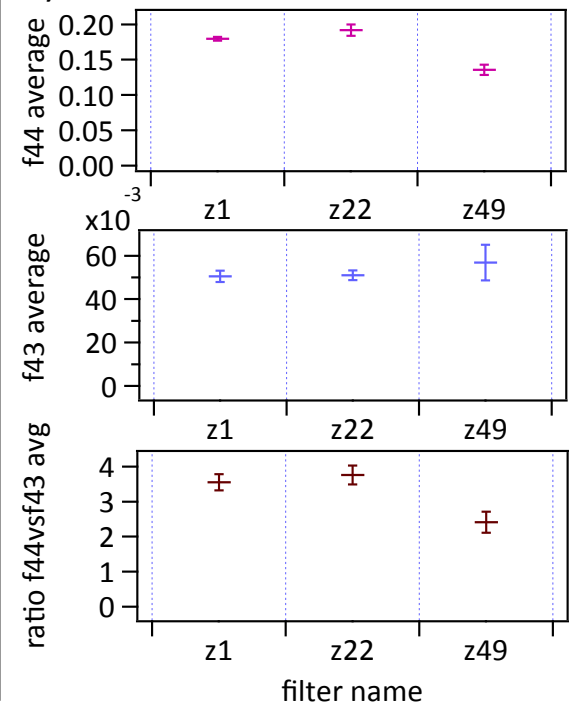

Fig. S 4. Fractions of $m / z 43$ and 44 in the organic spectra of three different filter samples (z1, z22 and z49). All three filters contain ambient aerosol particles sampled in Zurich, CH. Samples z1 and z22 were taken in winter and sample z49 was taken in summer. The filters were extracted into a liquid solution and subsequently nebulised to be able to measure them with an ACSM. For method description refer to Daellenbach et al. (2014). (a) $\mathrm{f} 44$, f43 and ratio of $\mathrm{f} 44 \mathrm{vs} \mathrm{f} 43$ at different vaporiser temperature settings for the three different filters. Each spectrum was averaged for $3 \times 10 \mathrm{~min}$. (b) Average f44, f43 and ratio of f44 vs f43 over the measurements with vaporiser temperatures between $550^{\circ} \mathrm{C}$ and $660^{\circ} \mathrm{C}$ (possible error margin of the ACSM temperature reading). The error bars show the first standard deviation.

Tab. S 5. Correlations $\left(\mathrm{R}^{2}\right)$ between factors from three factor PMF analysis with external measurements.

\begin{tabular}{lllll}
\hline $\mathbf{R}^{2}$ & $\begin{array}{l}\text { HOA }- \\
\mathbf{B C}_{\mathbf{f f}}\end{array}$ & $\begin{array}{l}\text { HOA }- \\
\mathbf{N O}_{\mathbf{x}}\end{array}$ & $\begin{array}{l}\mathbf{B B O A} \\
\mathbf{B C}_{\mathbf{w b}}\end{array}$ & $\begin{array}{l}\mathbf{O O A}- \\
\mathbf{S O}_{4}\end{array}$ \\
\hline ToF & 0.41 & 0.49 & 0.88 & 0.51 \\
AMS (UMR) & 0.56 & 0.60 & 0.86 & 0.56 \\
$\# 1$ & 0.67 & 0.62 & 0.93 & 0.72 \\
$\# 2$ & 0.58 & 0.60 & 0.93 & 0.52 \\
$\# 3$ & 0.44 & 0.44 & 0.91 & 0.71 \\
$\# 4$ & 0.63 & 0.66 & 0.93 & 0.54 \\
$\# 5$ & 0.53 & 0.60 & 0.86 & 0.76 \\
$\# 6$ & 0.53 & 0.52 & 0.87 & 0.73 \\
$\# 7$ & 0.43 & 0.46 & 0.87 & 0.72 \\
$\# 8$ & 0.61 & 0.54 & 0.88 & 0.72 \\
$\# 9$ & 0.49 & 0.48 & 0.85 & 0.75 \\
$\# 10$ & 0.62 & 0.70 & 0.91 & 0.75 \\
$\# 11$ & 0.64 & 0.61 & 0.84 & 0.74 \\
$\# 12$ & 0.52 & 0.54 & 0.91 & 0.78 \\
$\# 13$ & 0.53 & 0.53 & 0.86 & 0.59 \\
\hline
\end{tabular}



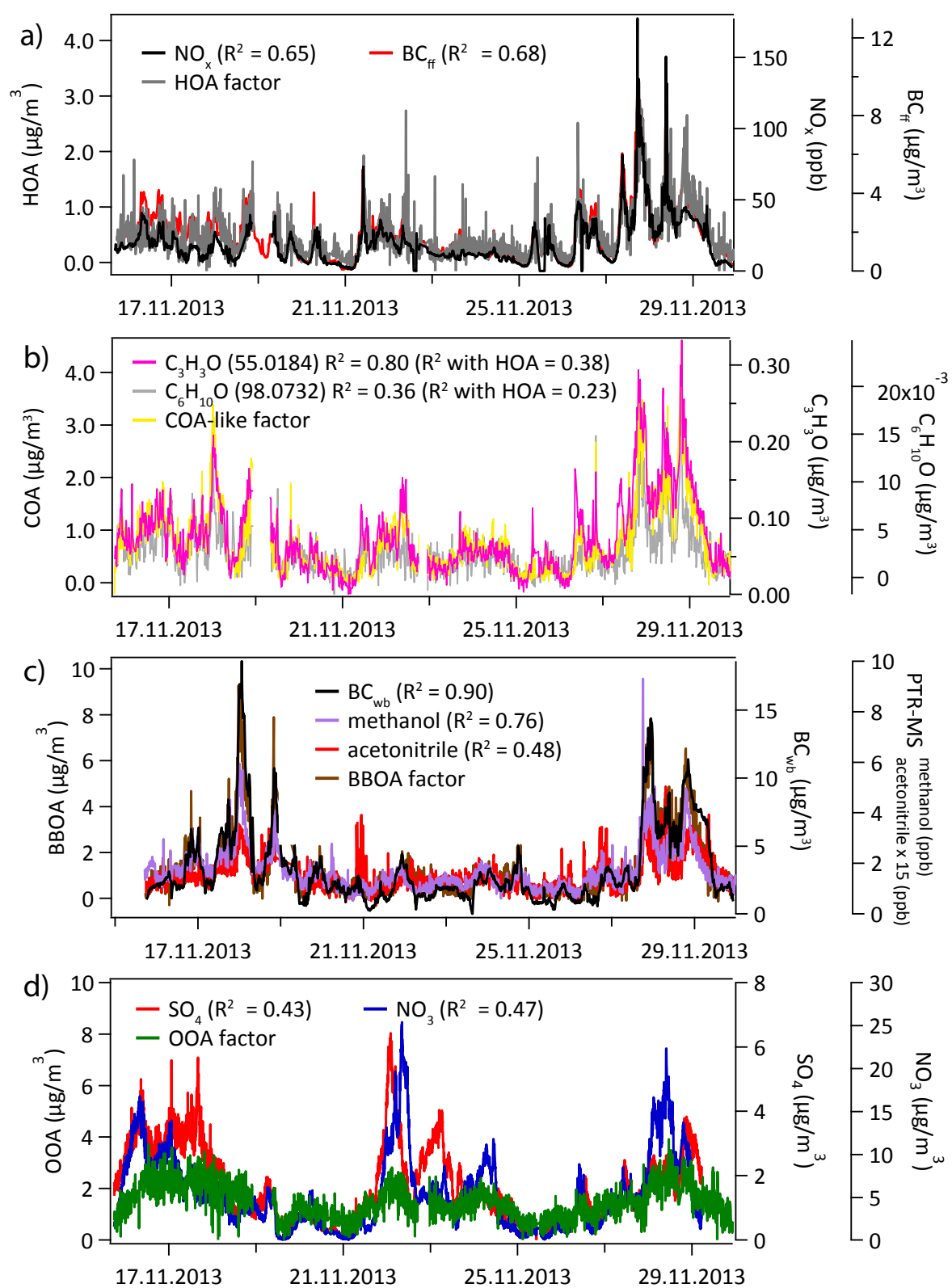

Fig. S 5. Time series correlations between factors from HR PMF analysis with external measurements during the whole two weeks of experiment. Corresponding $\mathrm{R}^{2}$ values are given in the plot. (a) HOA factor (grey) plotted together with $\mathrm{NO}_{\mathrm{x}}$ (black) measured with the $\mathrm{NO}_{\mathrm{x}}$ analyser and $\mathrm{BC}_{\mathrm{ff}}$ (red) time trace from the $\mathrm{BC}$ source apportionment of the Aethalometer data. (b) COA-like factor (yellow) plotted together with time trace of $\mathrm{C}_{3} \mathrm{H}_{3} \mathrm{O}^{+}$ion (pink) and $\mathrm{C}_{6} \mathrm{H}_{10} \mathrm{O}^{+}$ion (grey) from the AMS HR analysis. Coefficients of determination ( $\mathrm{R}^{2}$ ) with COA-like and HOA factors are given in the plot. (c) BBOA factor (brown) plotted together with time traces of gaseous methanol (violet) and acetonitrile (red), both measured by the PTR-MS, and $\mathrm{BC}_{\mathrm{wb}}$ (black) from the $\mathrm{BC}$ source apportionment of the Aethalometer data. (d) OOA factor (green) plotted together with inorganic nitrate (blue) and sulphate (red) measured by the HR-AMS. 


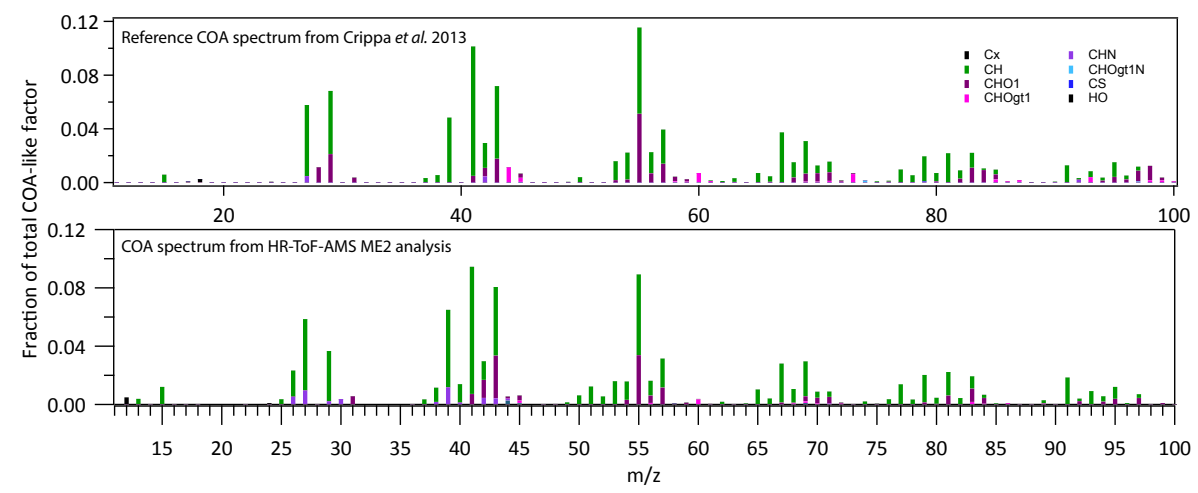

Fig. S 6. High-resolution COA factor spectrum from Crippa et al. (2013) (top) and from this study (bottom).

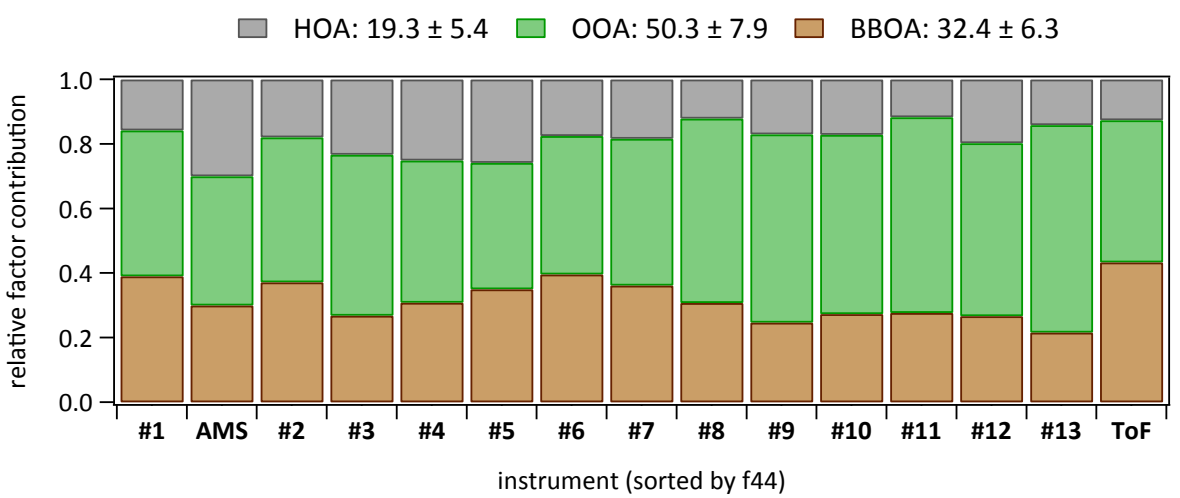

Fig. S 7. Relative contributions of HOA (grey), OOA (green) and BBOA (brown) factors from a three factor PMF solution without constraints for all 15 instruments (sorted by total f44). The shown AMS solution is from the analysis of the UMR AMS data set. Average contributions and the first standard deviation are given in the legend. 


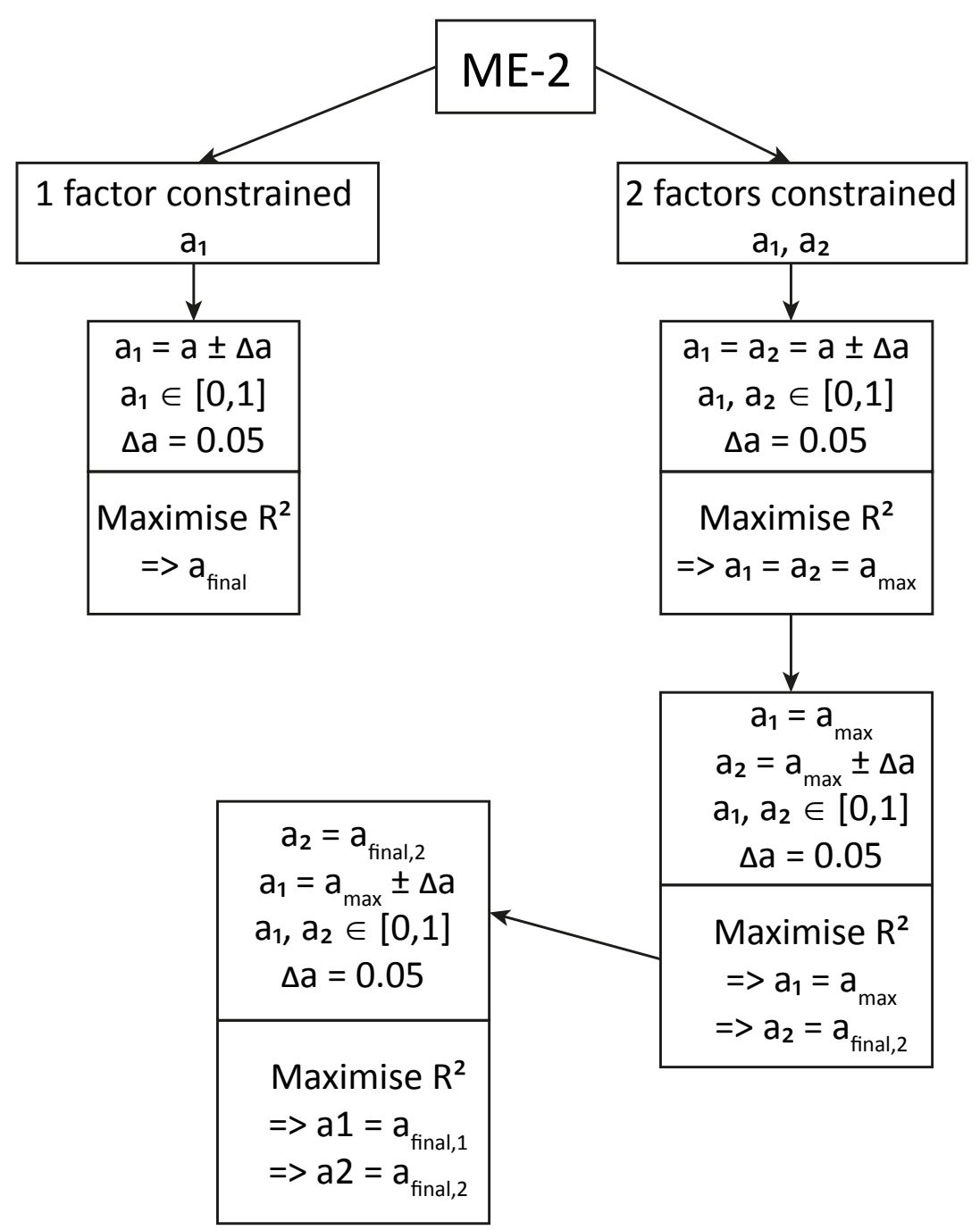

Fig. S 8. Flowchart showing the procedure applied to find the ideal $a$ value for ME-2 runs with one or two constrained anchor profiles. 

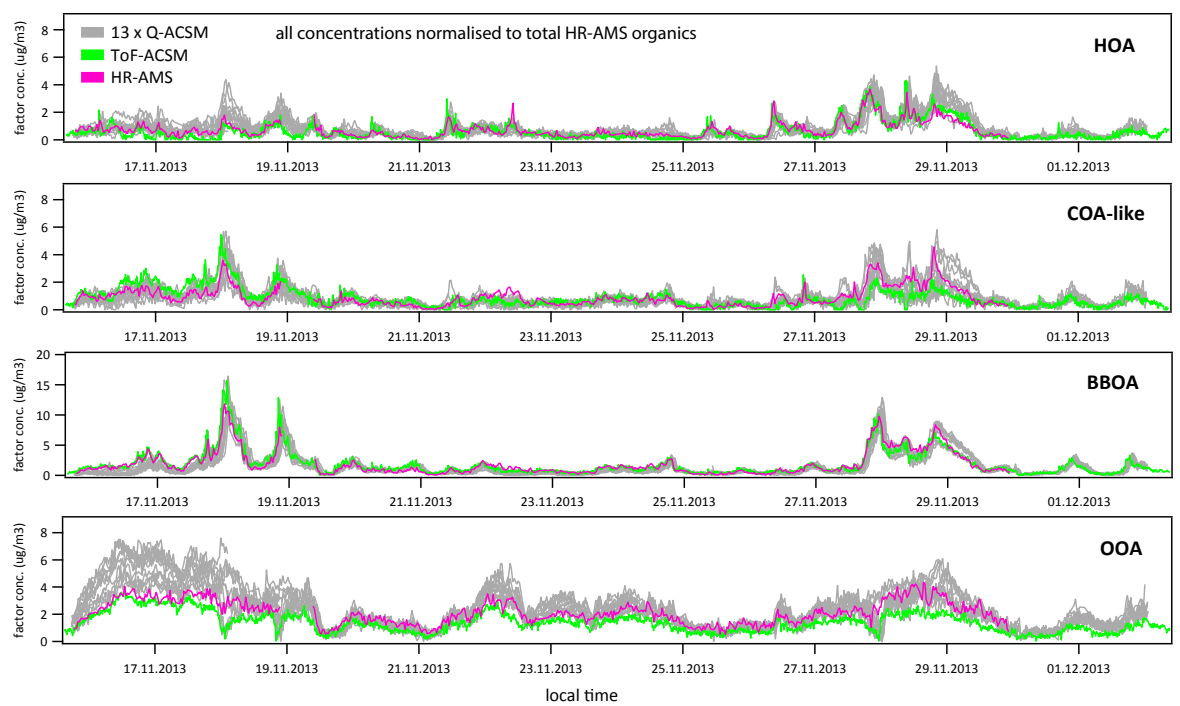

Fig. S 9. Full absolute time series of all four ME2 factors in $\mu \mathrm{g} / \mathrm{m}^{3}$ (from top to bottom: HOA, COA-like, BBOA and OOA) normalised to the same total organic concentrations (reference: HR-ToF-AMS). Pink: HR-ToF-AMS, green: ToF-ACSM, grey: all 13 Q-ACSMs. 

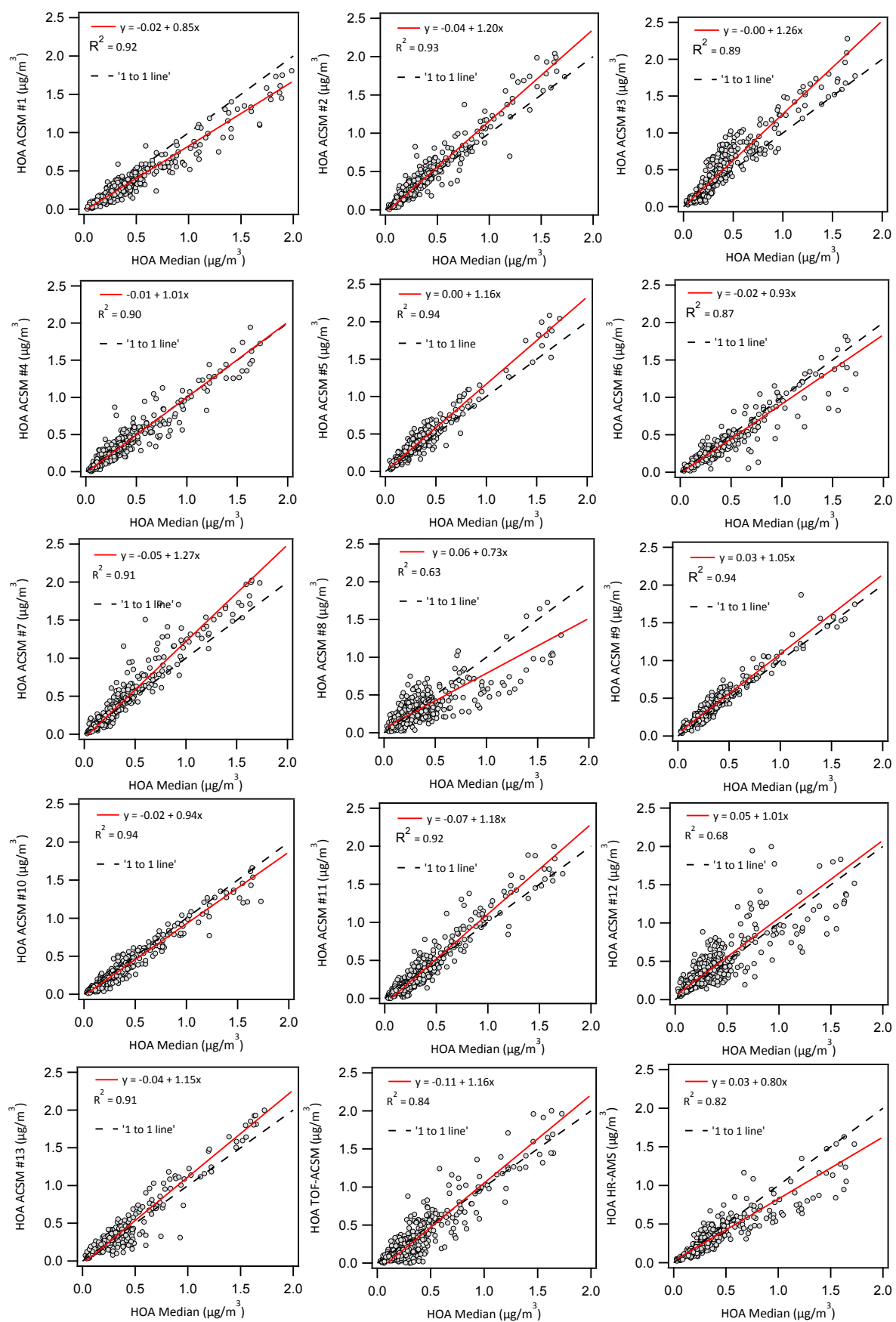

Fig. S 10. Correlations of normalised HOA factor time series (reference: total organic mass of HR-ToF-AMS) of all instruments (name indicated in the y label) to the median of all instruments. Slopes and coefficients of correlation $\left(\mathrm{R}^{2}\right)$ are given in the plots. The black dashed line indicates the $1: 1$ line. 

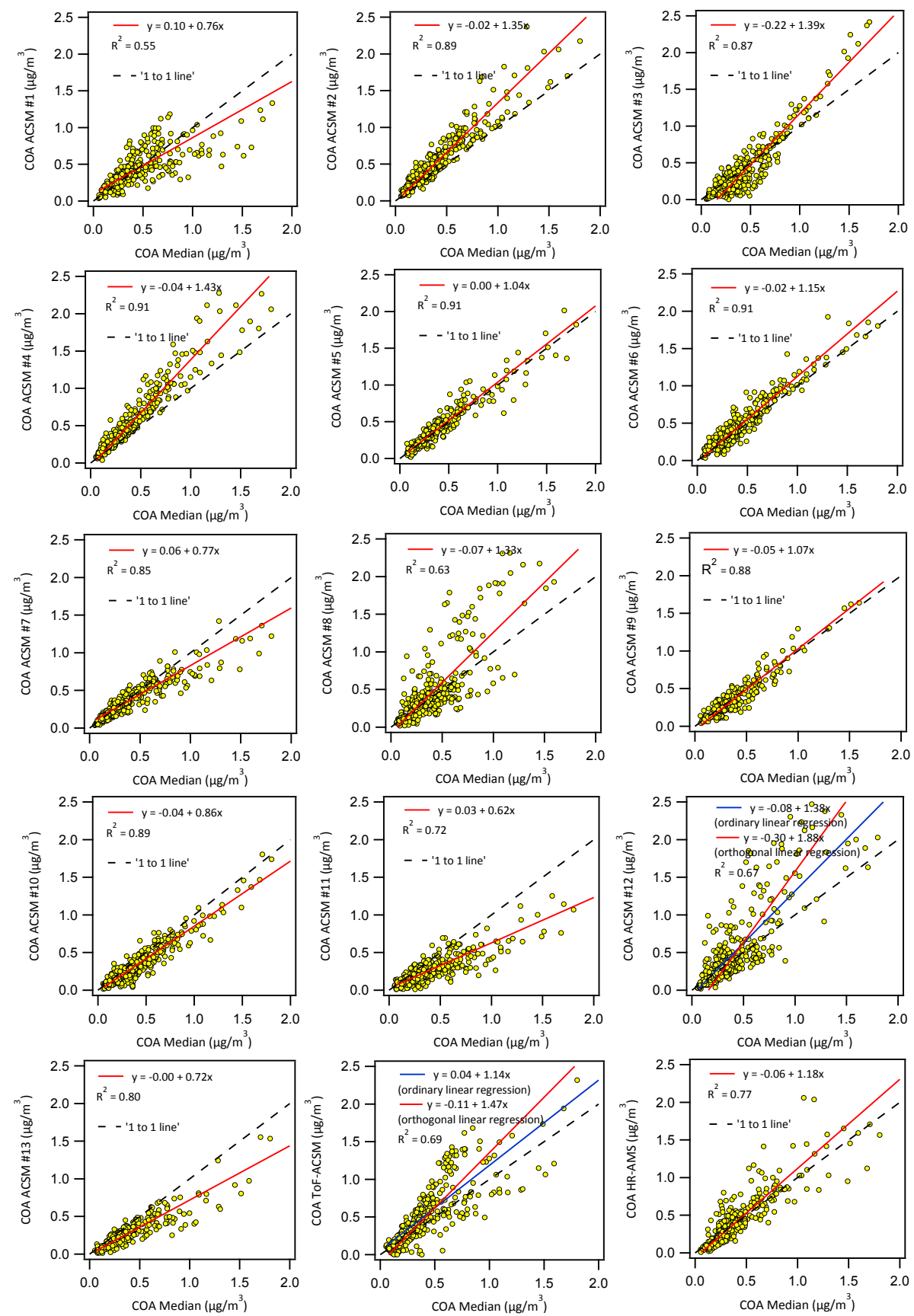

Fig. S 11. Correlations of normalised COA factor time series (reference: total organic mass of HR-ToF-AMS) of all instruments (name indicated in the y label) to the median of all instruments. Slopes and coefficients of correlation $\left(\mathrm{R}^{2}\right)$ are given in the plots. The black dashed line indicates the $1: 1$ line. 

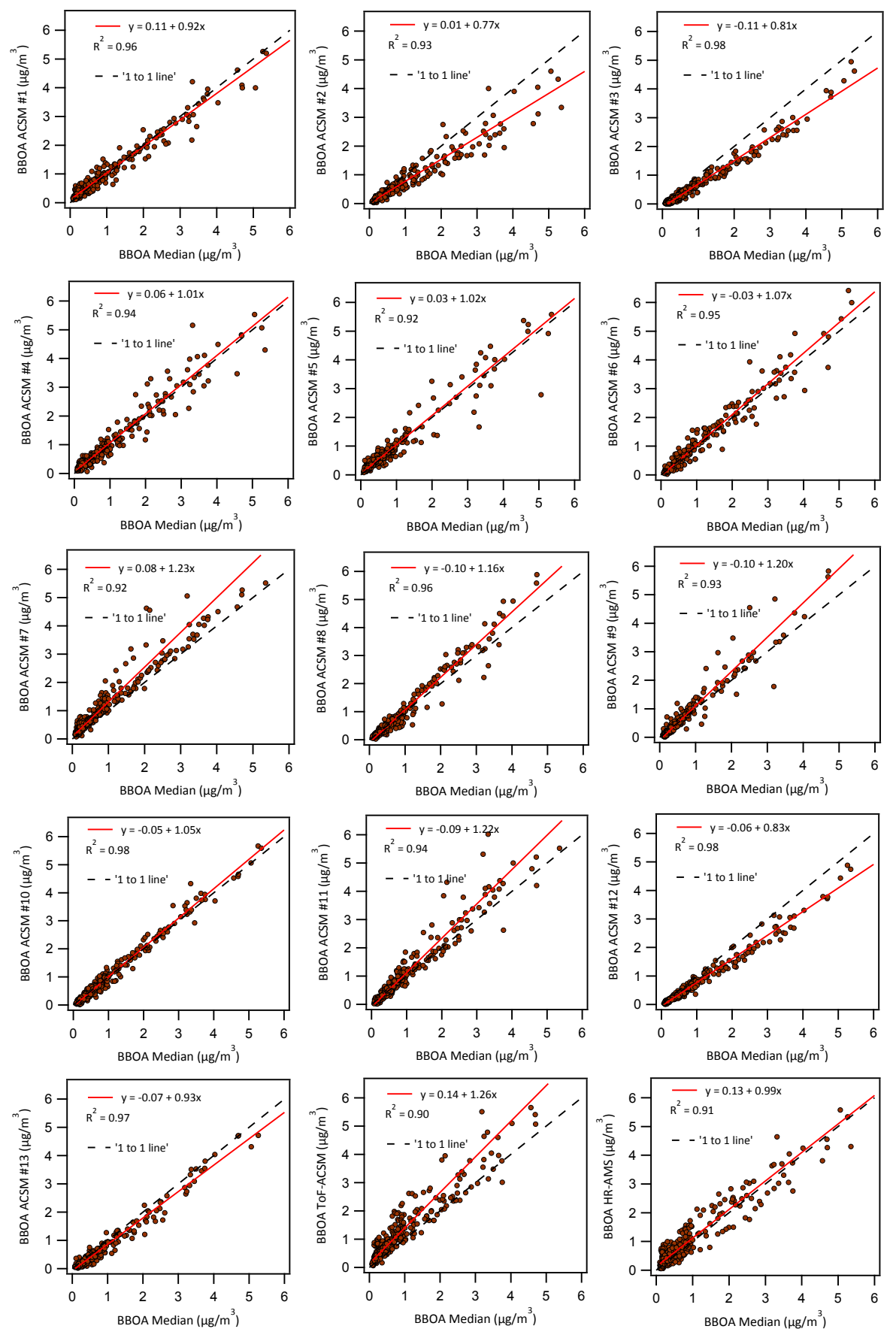

Fig. S 12. Correlations of normalised BBOA factor time series (reference: total organic mass of HR-ToF-AMS) of all instruments (name indicated in the $y$ label) to the median of all instruments. Slopes and coefficients of correlation $\left(\mathrm{R}^{2}\right)$ are given in the plots. The black dashed line indicates the $1: 1$ line. 

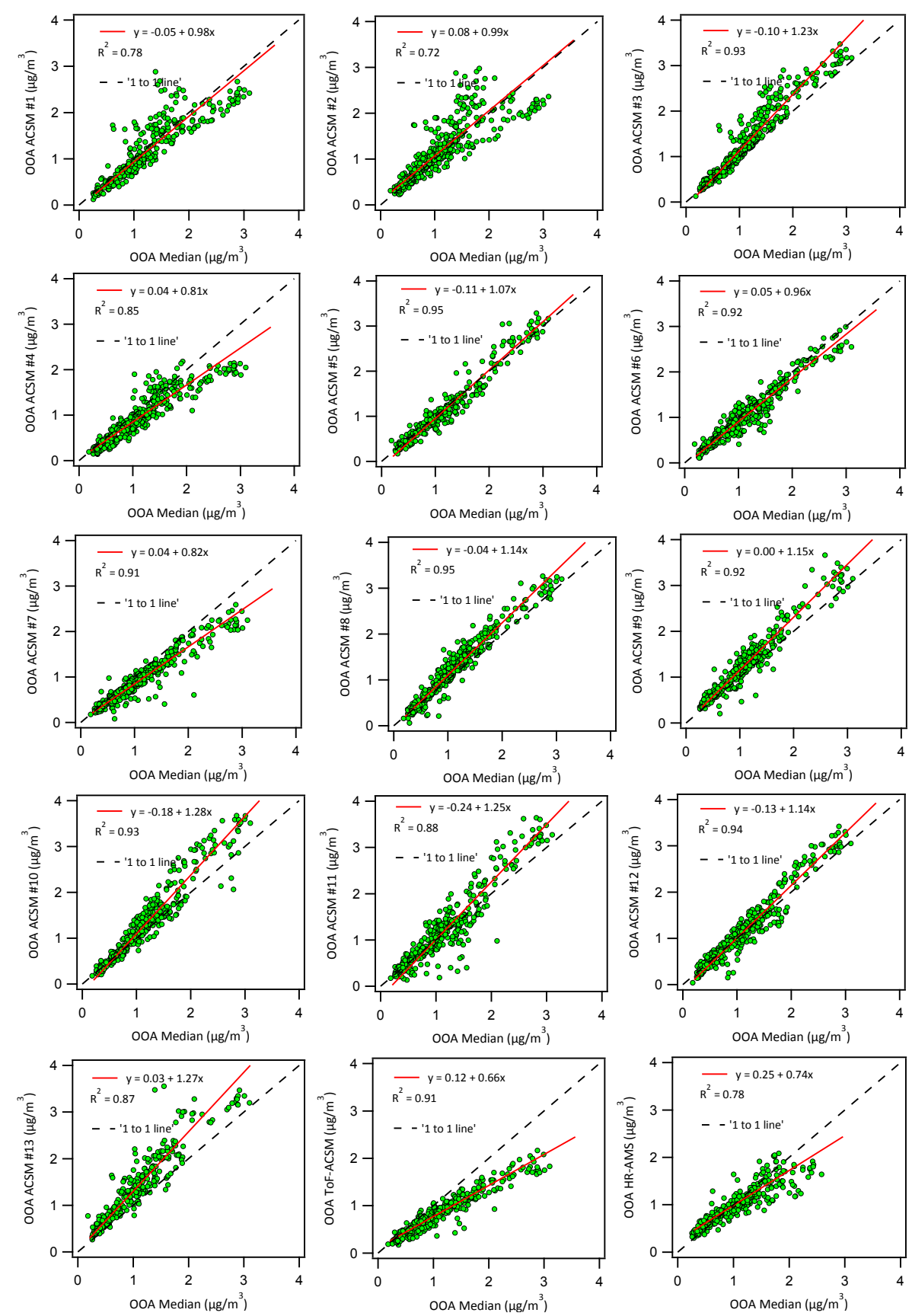

Fig. S 13. Correlations of normalised OOA factor time series (reference: total organic mass of HR-ToF-AMS) of all instruments (name indicated in the y label) to the median of all instruments. Slopes and coefficients of correlation $\left(\mathrm{R}^{2}\right)$ are given in the plots. The black dashed line indicates the $1: 1$ line. 

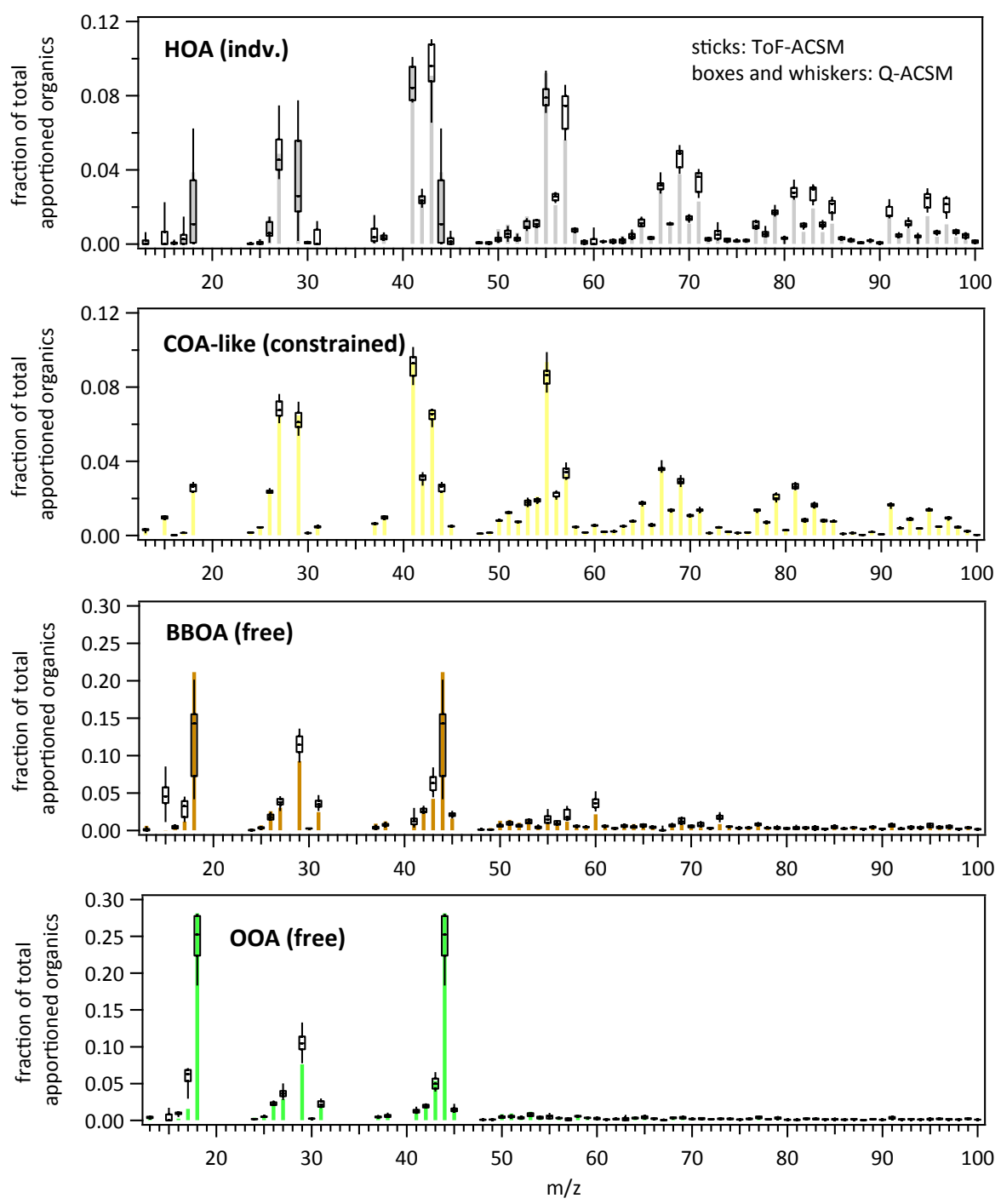

Fig. S 14. ME2 source spectra of the ToF-ACSM solution (sticks). The boxes and whiskers show the IQR and the full range of the Q-ACSM spectra, respectively. The line in the box indicates the median of all Q-ACSM. From top to bottom: HOA, COA-like, BBOA and OOA.

Tab. S 6. Average factor concentrations with first standard deviation in $\mu \mathrm{g} / \mathrm{m}^{3}$. This combines the uncertainties of the source apportionment with the uncertainties of the total organic mass discussed in part 1 of this study by Crenn et al. (2015).

\begin{tabular}{lll}
\hline factor & $\begin{array}{l}\text { average concentration } \\
\left(\boldsymbol{\mu g} / \mathbf{m}^{3}\right)\end{array}$ & $\begin{array}{l}\text { first standard devia- } \\
\text { tion }\left(\boldsymbol{\mu g} / \mathbf{m}^{3}\right)\end{array}$ \\
\hline HOA & 1.01 & 0.25 \\
COA-like & 1.06 & 0.35 \\
OOA & 2.90 & 0.51 \\
BBOA & 2.11 & 0.73 \\
\hline
\end{tabular}



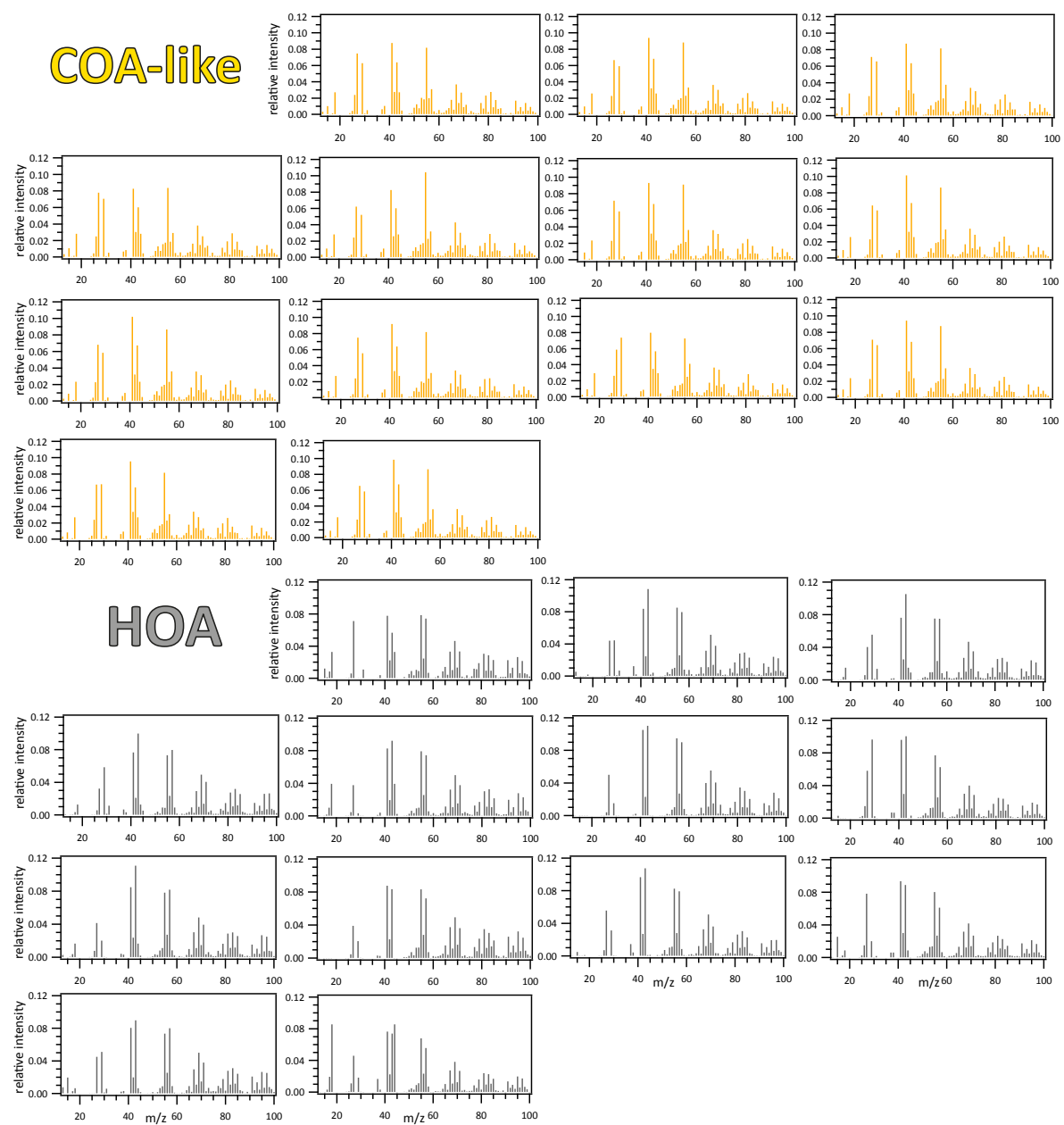

Fig. S 15. Source profiles from ME-2 "best solutions" of all 13 Q-ACSMs. All normalised to 1. COA-like (yellow) and HOA (grey). Organised from left to right and top to bottom according to the instrument numbers \#1 - \#13. 


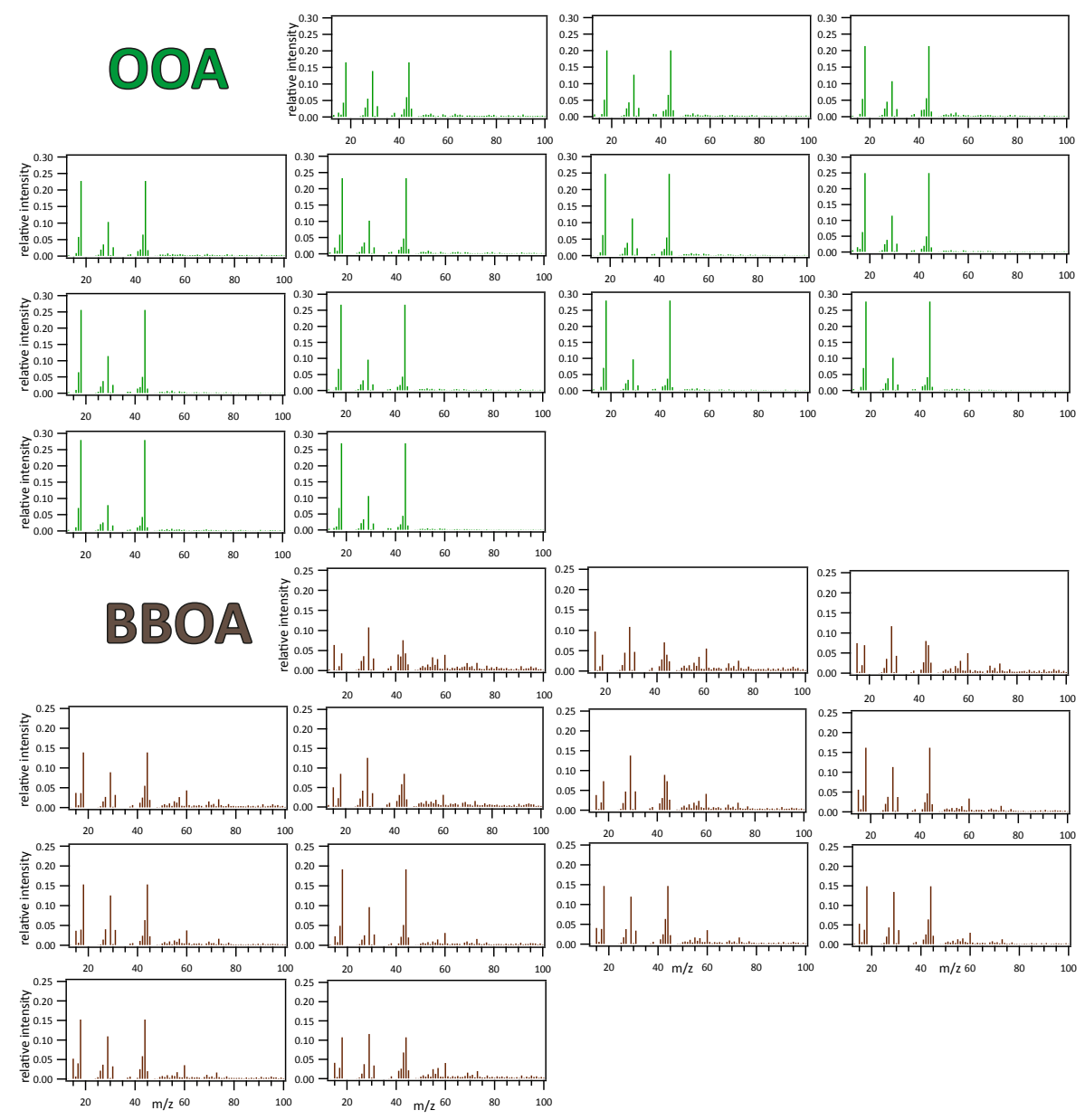

Fig. S 16. Source profiles from ME-2 "best solutions" of all 13 Q-ACSMs. All normalised to 1. OOA (green) and BBOA (brown). Organised from left to right and top to bottom according to the instrument numbers \#1 - \#13.

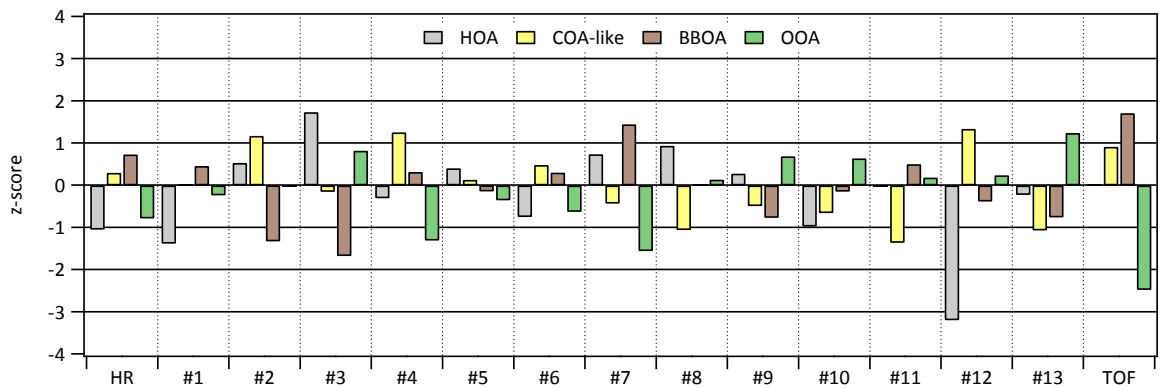

Fig. S 17. $z$-score values for all factors and all instruments. $z$-score values were calculated with median contribution as reference and standard deviations determined with the robust algorithm A of ISO 13528 according to Eq. S1. $|z| \leq 1$ : "ok", $1<|z| \leq 2$ : "acceptable", $2<|z| \leq 3$ : "warning", $|z|>3$ : "action" (see §7.4.2, ISO13528 (2005)). 
2 Update of the Q-ACSM PMF export function in recent analysis software update (version 1.5.5.0) and its influence on the presented dataset

After the presented work was performed an update of the analysis software was released introducing changes of the PMF matrix calculation procedure. While in the former version the same relative ion transmission (RIT) curve (red curve in Fig. S18a) was applied to all datasets, the updated version introduces an individual correction (blue curve in Fig. S18a) for each instrument with the goal to reduce spectral differences between instruments. All data discussed in this manuscript, however, was calculated with version 1.5.3.2, i.e. with the same RIT applied. Fig. S18a shows both RITs of the instrument (\#9) with the highest deviation between "old" and "new" calculation of all 13 Q-ACSMs. Note the error range for the calculated curve. In almost all cases (except \#10 \& \#13) the "new" calculation leads to lower intensities of the $m / z$ channels $>55$. The error matrix calculation is equally affected, however there the change is about a factor two lower. This means the $\mathrm{S} / \mathrm{N}$ of the $\mathrm{m} / z>55$ was slightly overestimated in the data presented in the manuscript compared to if the data was calculated with the "new" procedures. Figure S18b shows relative changes of PMF organic matrix and error matrix and Fig. S18c shows the absolute change of the spectrum for the most severely affected instrument \#9.

What are possible consequences on the presented work? On the one hand the presented uncertainties may be slightly lower if the "new" calculation was applied because input spectra are more similar, but on the other hand a lower $\mathrm{S} / \mathrm{N}$ at higher $m / z$ may lead to slightly larger residuals and hence to slightly larger deviations between solutions. A comparison of source apportionment results of one instrument with matrices calculated with both software versions showed no significant differences in neither factor contributions, factor time series nor factor profiles.

All Q-ACSM source apportionment results published so far used the "old" calculation method. 

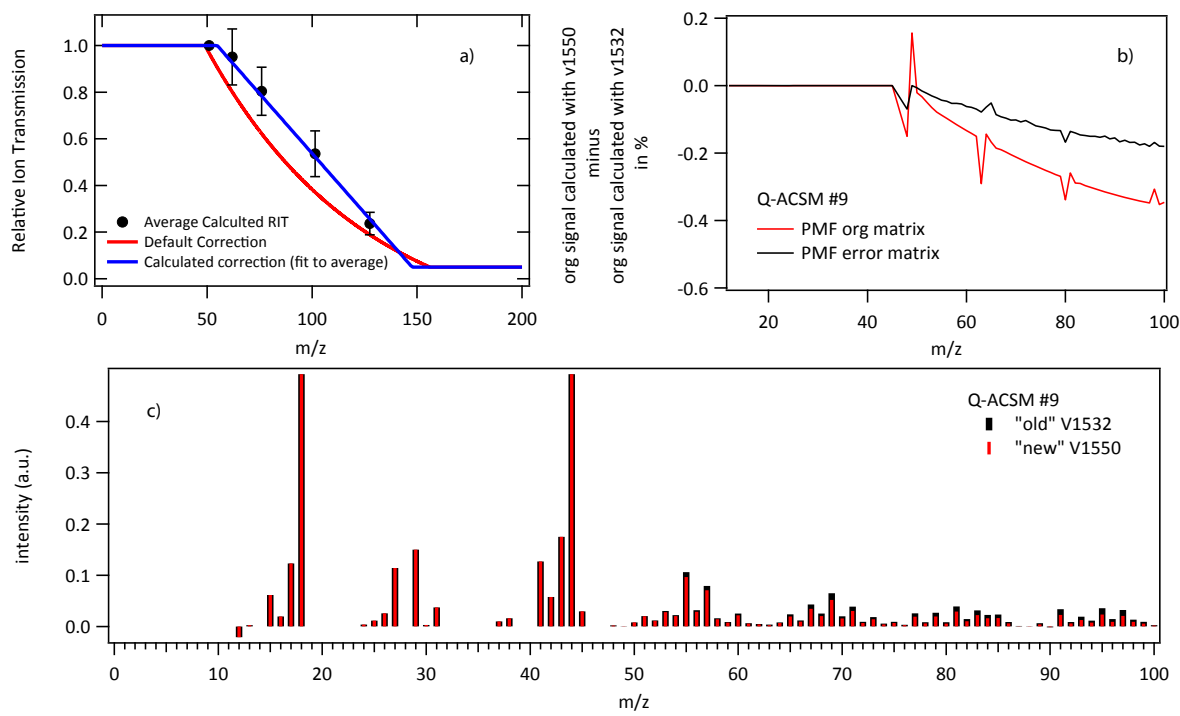

Fig. S 18. (a) Relative ion transmission (RIT) curves of instrument \#9 with the largest deviation between default and calculated correction (red and blue curve). Black dots and error bars were calculated from naphthalene fragments in the background spectra. Red curve: default correction used in analysis version 1.5.3.2, i.e. for all data presented in this manuscript. Blue curve: calculated correction from fit to the measured data. This correction is applied in version 1.5.5.0 of the analysis software. (b) Relative change of PMF organic matrix (red) and PMF error matrix (black) as function of $\mathrm{m} / z$ for the two software versions. Note that the relative change of the error is smaller than the relative change of the signal, leading to decreased $\mathrm{S} / \mathrm{N}$ in this case. (c) Spectrum (one data point) of instrument \#9 calculated with the two versions. Red was calculated with version 1.5.5.0, black with 1.5.3.2. Intensities from the newer software version are slightly lower. 


\section{HR-AMS PMF analysis diagnostics}

A four factor solution (HOA,COA,BBOA,OOA) is presented as best solution in the manuscript. The applied HOA and COA anchor profiles were taken from a higher order PMF solution ( 8 factors) and constrained with $a=0$ in the 4 factor constrained run of the ME-2 package. In the following more detail about how and why the 4 presented solution was chosen is presented.

\subsection{4 factor unconstrained PMF}

Mean profile and diurnal cycle of 10 seed runs with 4 unconstrained factors are shown in Fig. S19 including first standard deviations (error bars). While factor 1 and factor 2 are relatively stable over the 10 seeds factor 3 and factor 4 vary significantly. Both show similar profiles (with elevated f60) and diurnal trends indicating a split of a BBOA factor and possibly some mixing with factor $2(\mathrm{OOA})$ or other not yet resolved factors.

The overview about the factor contributions in the seed runs (Fig. S20) shows a similar picture: stable contributions of the HOA factor, some variation of the OOA factor and large variations of the rest. All solutions show only little difference in $\mathrm{Q} / \mathrm{Q}_{\exp }$ values (top right of Fig. S20). Comparison with external data yields good correlations of factor 1 with $\mathrm{NO}_{\mathrm{x}}$ and $\mathrm{BC}_{\mathrm{ff}}$, factor 2 and sulphate and between $\mathrm{BC}_{\mathrm{wb}}$ and factors 3 and 4. However, in any case correlations are less good than the ones shown for the solution presented in the manuscript in Tab. 2. 

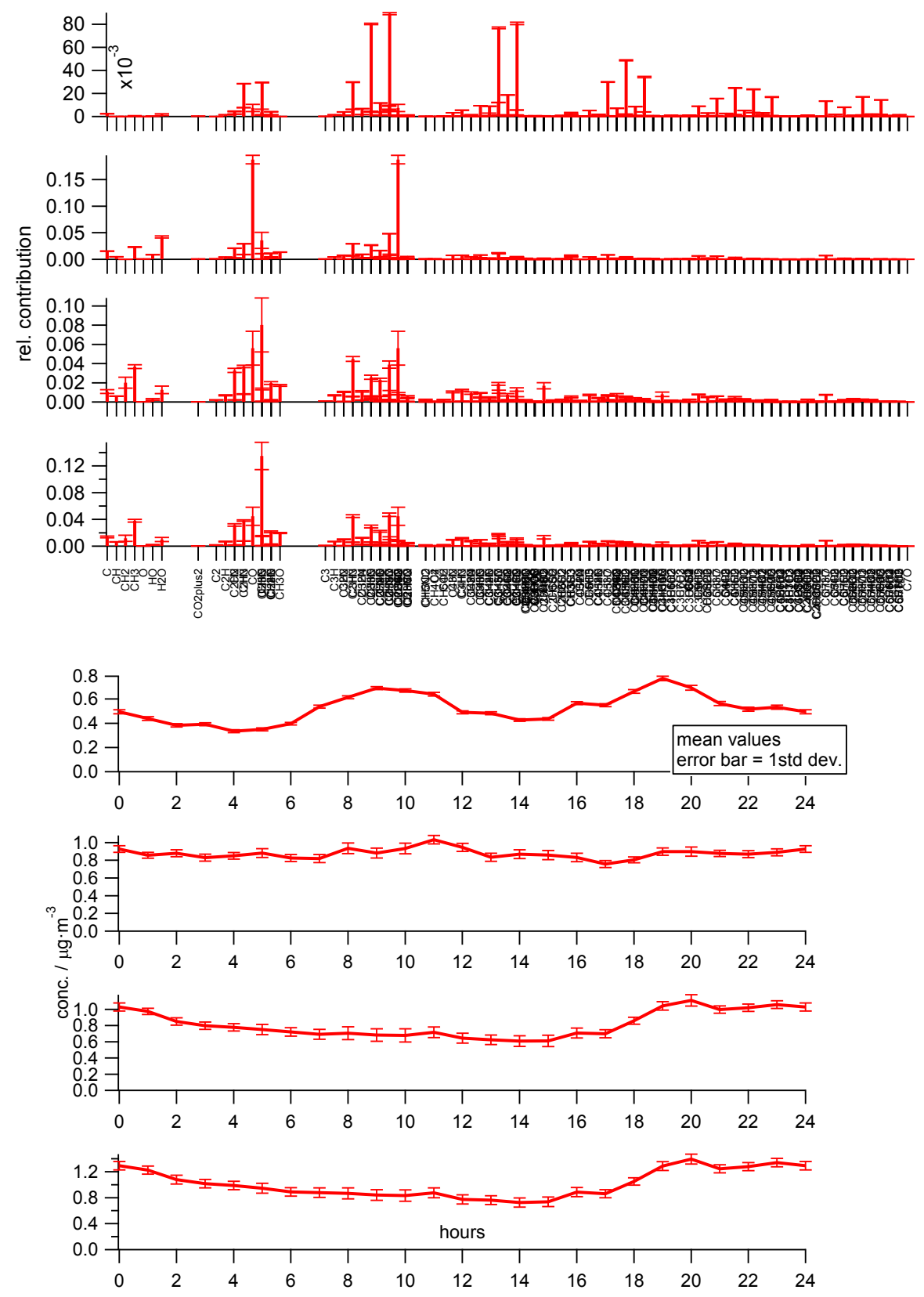

Fig. S 19. Top panel: mean spectra of the 4 factor unconstrained PMF (10 seeds). Bottom panel: mean diurnal cycles of the 4 factor unconstrained PMF (10 seeds) 


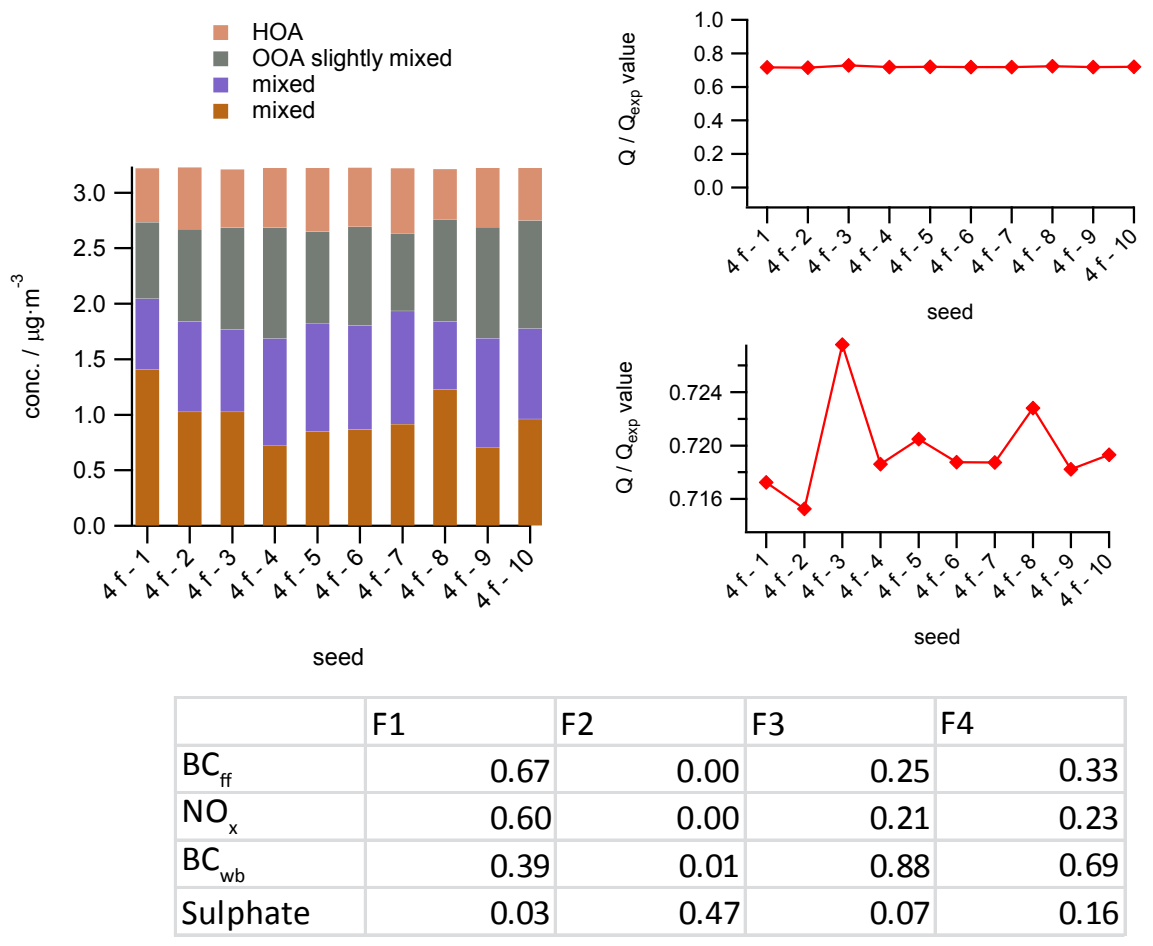

Fig. S 20. Top left: factor contributions of 10 seeds, 4 factor unconstrained PMF. Top right: Q/Q $\exp$ for the 10 different seeds. Bottom panel: $R^{2}$ coefficients of the four factors with external data. 


\subsection{5 factor unconstrained PMF}

An increase of the factor number to five still shows a stable factor 1 (HOA) and a factor 2 (OOA) with only small variability in all 10 seeds shown in the top left panel of Fig. $\mathrm{S} 21$. Factor contributions of all other factors also seem to be more stable than in the 4 factor unconstrained PMF but a look at profiles (middle panel of Fig. S21) and diurnal cycles (top right panel of Fig. S21) still points to factor mixing. The profile of factor 3 looks like a mixture of typical BBOA (high f60) and COA (high f55) and also the diurnal cycle shows peaks at lunch time and at dinner time overlayed by a large afternoon increase (possibly due to residential heating by wood combustion). Profile and diurnal cycle of factors 4 and 5 point towards a splitted BBOA with some contribution of OOA according to a comparison to external data. Coefficients of correlation are shown in the bottom panel of Fig. $\mathrm{S} 21$. The values are comparable to the 4 factor solution with the exception of a lower $R^{2}$ of the OOA with $\mathrm{SO}_{4}$. 

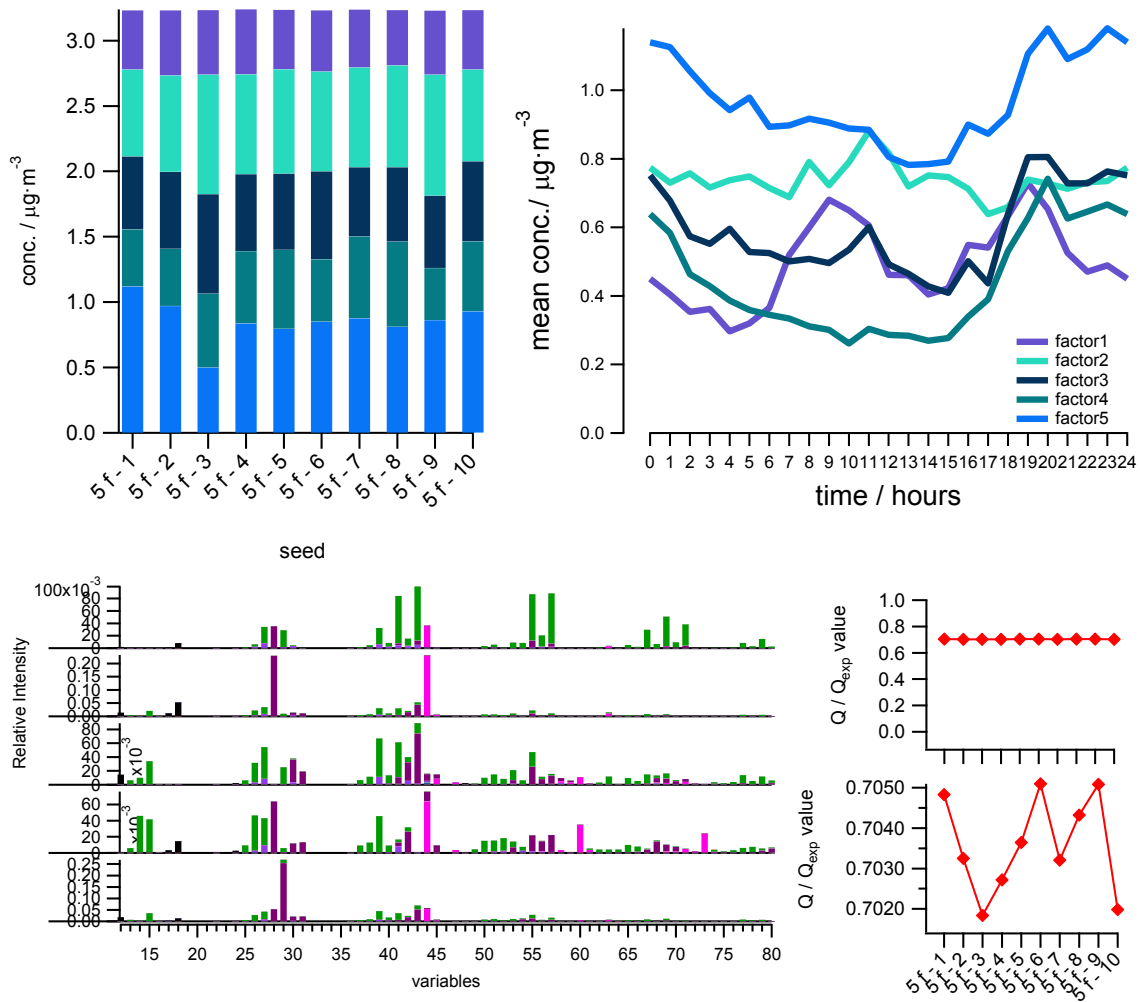

seed

\begin{tabular}{|l|l|l|l|l|l|l|l|}
\hline & F1 & & F2 & & & & \\
\hline $\mathrm{BC}_{\mathrm{ff}}$ & 0.68 & 0.15 & 0.32 & 0.25 & 0.25 \\
\hline $\mathrm{BC}_{\mathrm{wb}}$ & 0.33 & 0.32 & 0.75 & 0.88 & 0.71 \\
\hline $\mathrm{NO}_{\mathrm{x}}$ & 0.63 & 0.06 & 0.23 & 0.22 & 0.16 \\
\hline Sulphate & 0.01 & 0.34 & 0.18 & 0.05 & 0.27 \\
\hline
\end{tabular}

Fig. S 21. Top left: factor contributions of 10 seeds, 5 factor unconstrained PMF. Top right: diurnal cycles of the 5 unconstrained factors. Middle left: profiles of an unconstrained 5 factor solution. Middle right: $\mathrm{Q} / \mathrm{Q}_{\exp }$ for the 10 different seeds. Bottom panel: $R^{2}$ coefficients of the five factors with external data. 


\subsection{8 factor unconstrained PMF}

An investigation of unconstrained PMF solutions with higher numbers of factors resulted in a separation of a clean COA factor in addition to the HOA factor which already was resolved well in the 4 factor unconstrained solutions. The top right panel of Fig. S22 shows the profiles of such an 8 factor unconstrained PMF run. Here, factor 4 represents the COA factor which shows great similarities to previously published COA profiles (cf. Fig S6). In addition to the diurnal cycle of this COA factor (top right panel of Fig. S22), which shows clear lunch and dinner time peaks, an investigation of the residuals of an OA fragment typical for $\mathrm{COA}\left(\mathrm{C}_{3} \mathrm{H}_{3} \mathrm{O}^{+}\right)$ shows strong evidence for the validity of this factor. Residuals are discussed in Sect. 3.6 of the Supplementary material. The remaining factors in this 8 factor solution are nonphysical splits of BBOA (factors 5,6 \& 7) and OOA (factors $2 \& 8$ ) or a mix of primary OA with OOA which only has very low contributions to total OA (factor 1). These mixed and split factors vary a lot when the model is run several times with varying seeds (see Fig. S23) while for HOA and COA only two types of solutions exist. Only in the solutions denoted with a $\mathbf{B}$ the COA is well separated from the rest. In the other, less frequently appearing type part of the COA is still mixed with BBOA (see profiles in fig. S23).

Figure S24 shows the mean COA (bottom) and HOA (top) profiles extracted from the 8 seed runs belonging to $\mathbf{A}$ in Fig. S23. The first standard deviation is indicated by the vertical error bars. Note that these are not stacked HR spectra which can contain more than one important fragment at a given $m / z$. 

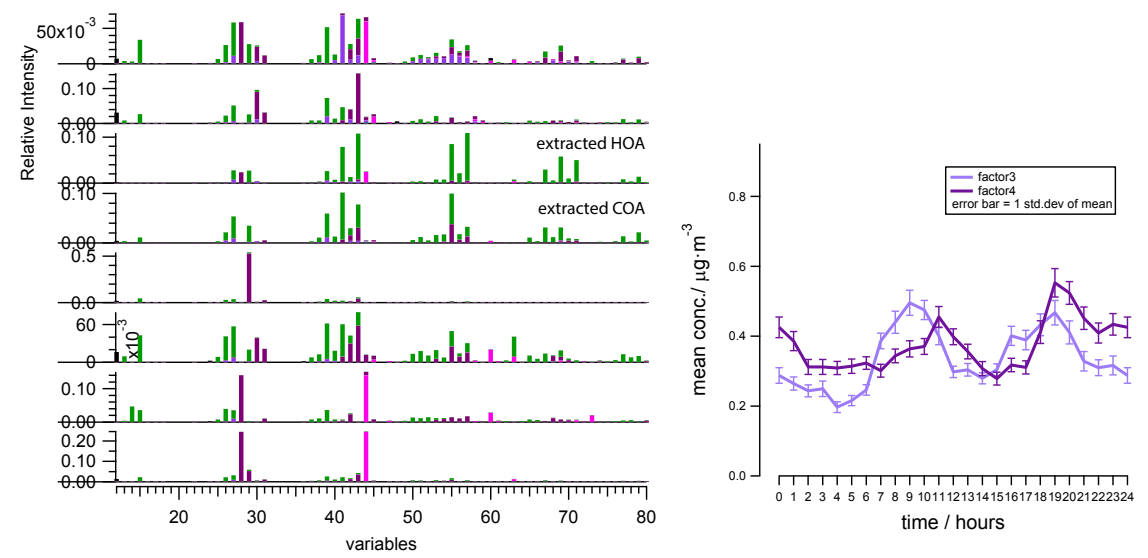

\begin{tabular}{|l|l|l|l|l|l|}
\hline & F1 & F2 & F3 & F4 \\
\hline $\mathrm{BC}_{\text {ff }}$ & 0.28 & 0.27 & 0.67 & 0.39 \\
\hline $\mathrm{NO}_{\mathrm{x}}$ & & 0.18 & 0.16 & 0.59 & 0.28 \\
\hline $\mathrm{BC}_{\mathrm{wb}}$ & & 0.49 & 0.55 & 0.25 & 0.53 \\
\hline Sulphate & & 0.05 & 0.40 & 0.01 & 0.12 \\
\hline
\end{tabular}

\begin{tabular}{|l|l|l|l|l|l|}
\hline & F5 & F6 & F7 & F8 \\
\hline 0.39 & 0.22 & 0.18 & 0.26 & 0.08 \\
\hline 0.28 & 0.65 & 0.12 & 0.22 & 0.02 \\
\hline 0.53 & 0.71 & 0.73 & 0.88 & 0.06 \\
\hline 0.12 & 0.18 & 0.08 & 0.06 & 0.41 \\
\hline
\end{tabular}

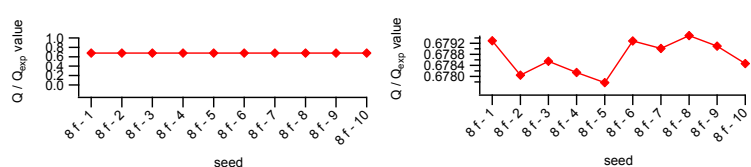

Fig. S 22. Top left: profiles of an unconstrained 8 factor solution. Top right: Diurnal cycles of the HOA and COA factor of the 8 factor unconstrained PMF. Middle panel: $R^{2}$ coefficients of the eight factors with external data. Bottom: Q/Q $\exp$ for the 10 different seeds. 


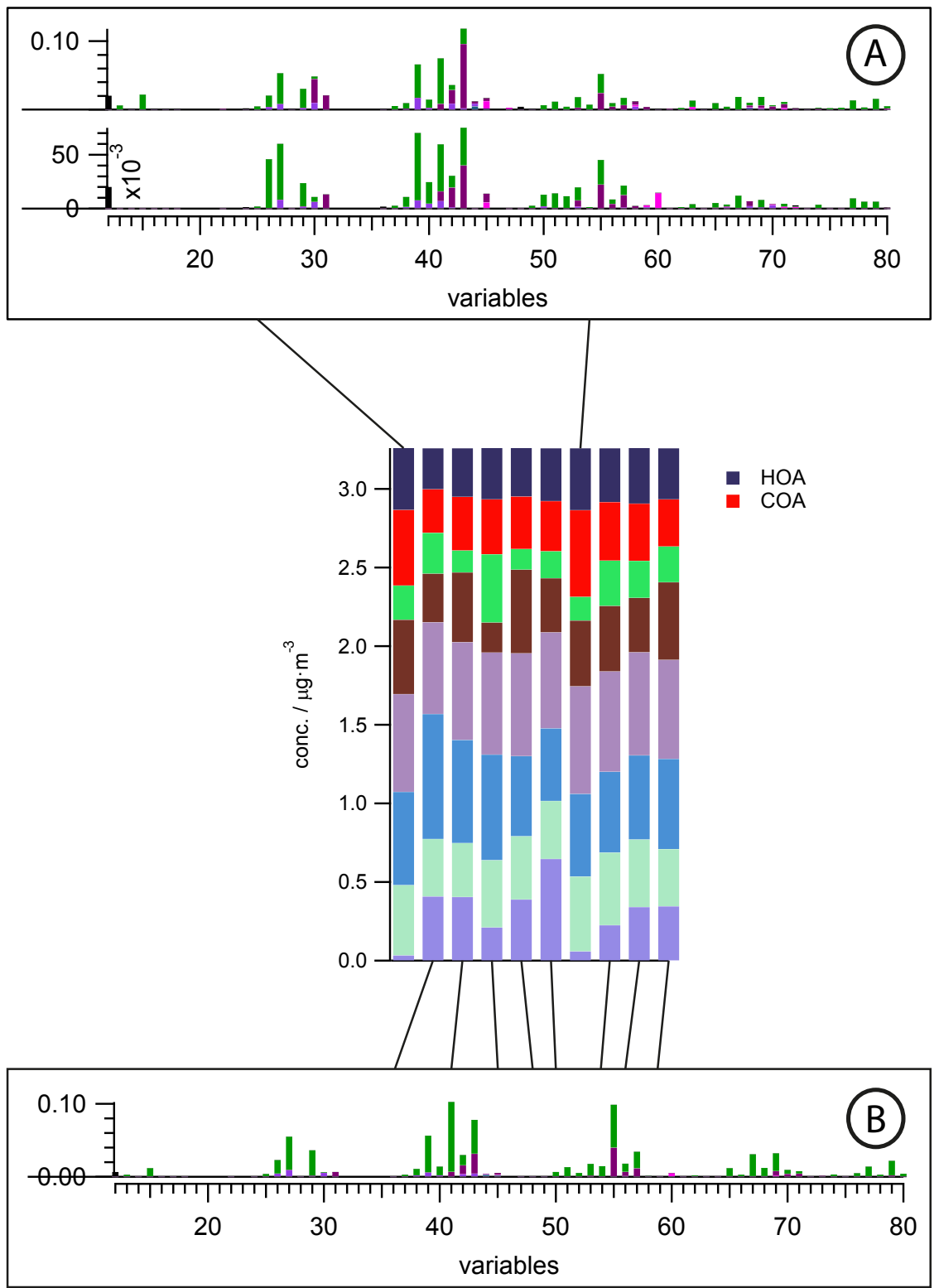

Fig. S 23. Two types of COA separation in the 8 factor unconstrained PMF. Type A shows an insufficient separation of COA and BBOA and is therefore not considered in the further analysis. Type B shows a good separation of COA. Variability of factor contributions of the 8 factor unconstrained PMF solution is shown in the center of the plot (10 seeds). 

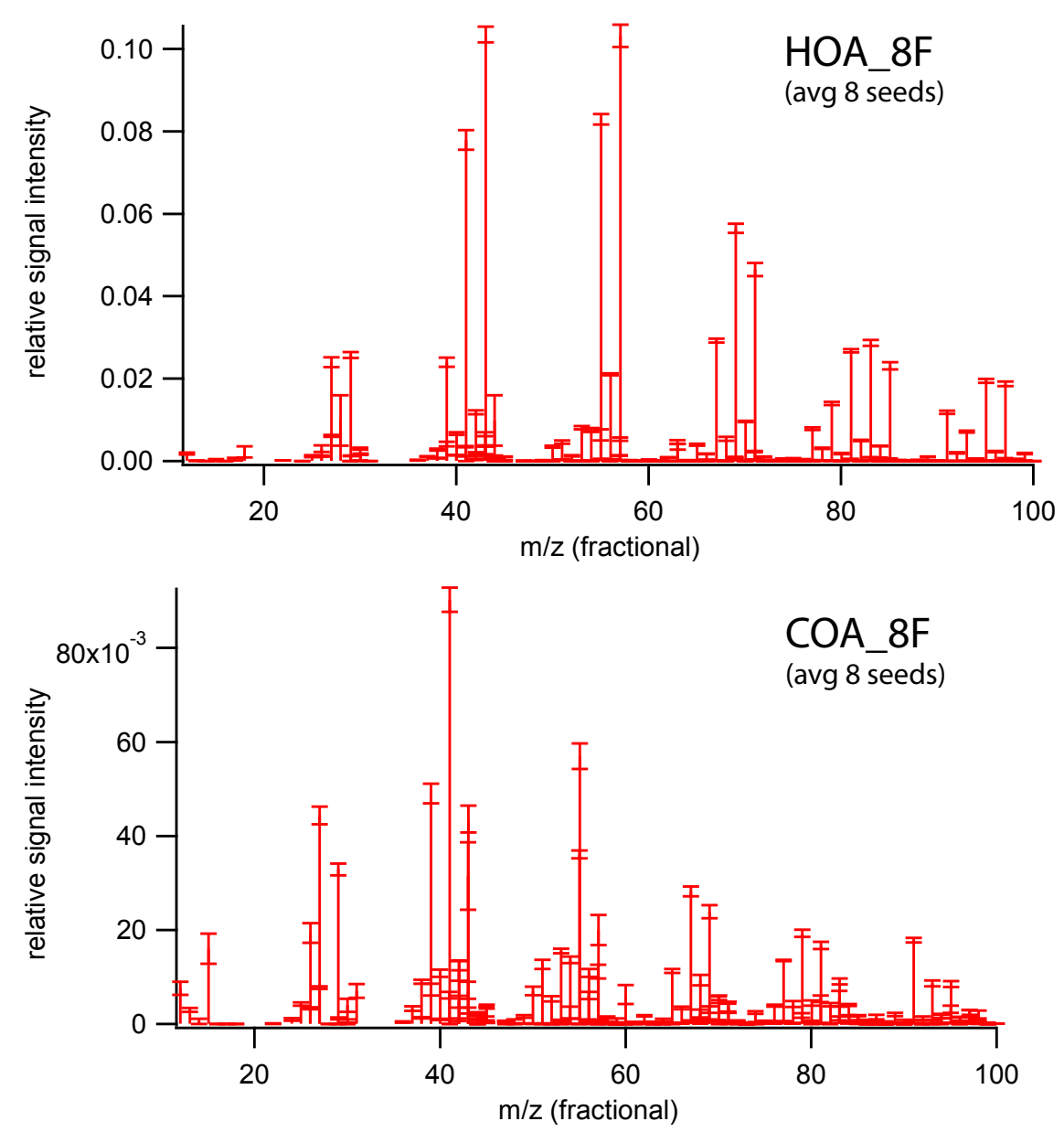

Fig. S 24. Average HR spectra of the extracted HOA and COA profiles from the 8 seeds belonging to type B (cf. Fig S23). 


\subsection{4 factor constrained PMF}

The 4 factor solution with constrained HOA and COA anchors taken from the 8 factor solutions are presented in the main text as best solution. Figure S25 shows the variability over 10 seeds. Some ME-2 runs show lower BBOA concentrations (e.g. seed t8). For these runs the covariance of the BBOA and OOA time series is increased and worse correlations of the OOA factor with inorganic secondaries but also of the BBOA factor with $\mathrm{BC}_{\mathrm{wb}}$ are observed. See bottom panel of Fig. S25 for the $R^{2}$ coefficients. Consequently, in the solutions with lower BBOA contributions, BBOA and OOA were considered not well separated. 


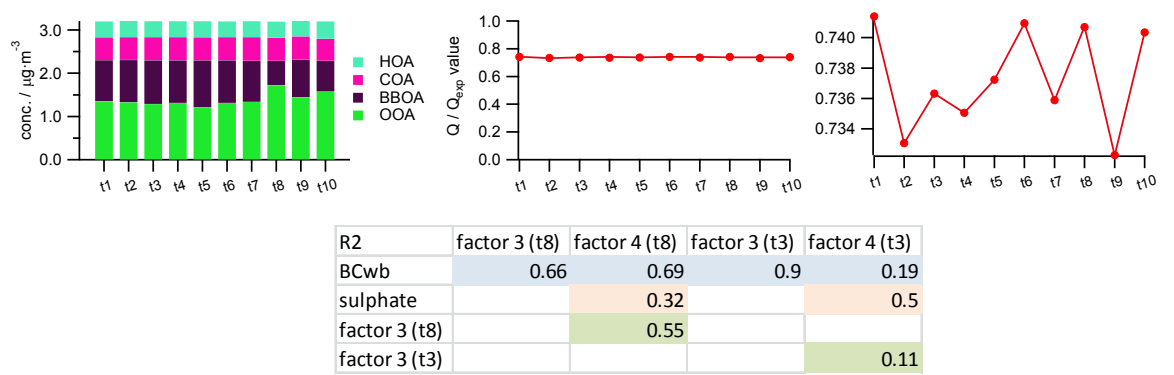

Fig. S 25. Top left: factor contributions of 10 seeds, 4 factor constrained PMF (ME-2). Top middle and right: Q/Qexp for the 10 different seeds. Bottom panel: $R^{2}$ coefficients of factors 3 (BBOA) and 4 (OOA) with external tracers and with each other for seed "t3" and seed "t 8 ". A comparison of the coefficients shaded with the same colours shows better model performance for seeds of type " $\mathrm{t} 3$ ". 


\subsection{5 factor constrained PMF}

The 5 factor constrained solution (anchors: COA and HOA from the 8 factor solution) shows a splitting of the BBOA factor with one of the splits containing most of the signals around $m / z 29$ (diurnal cycles, profiles and seed variations are shown in Fig S26). Additionally the correlations of OOA with sulphate decreased significantly compared to the 4 factor constrained solution $\left(R^{2}\left(\mathrm{SO}_{4}-\mathrm{OOA}\right)=0.26-0.30 \mathrm{de}-\right.$ pending on the seed). Contributions and time traces of HOA and COA are very similar to the 4 factor constrained solution. 

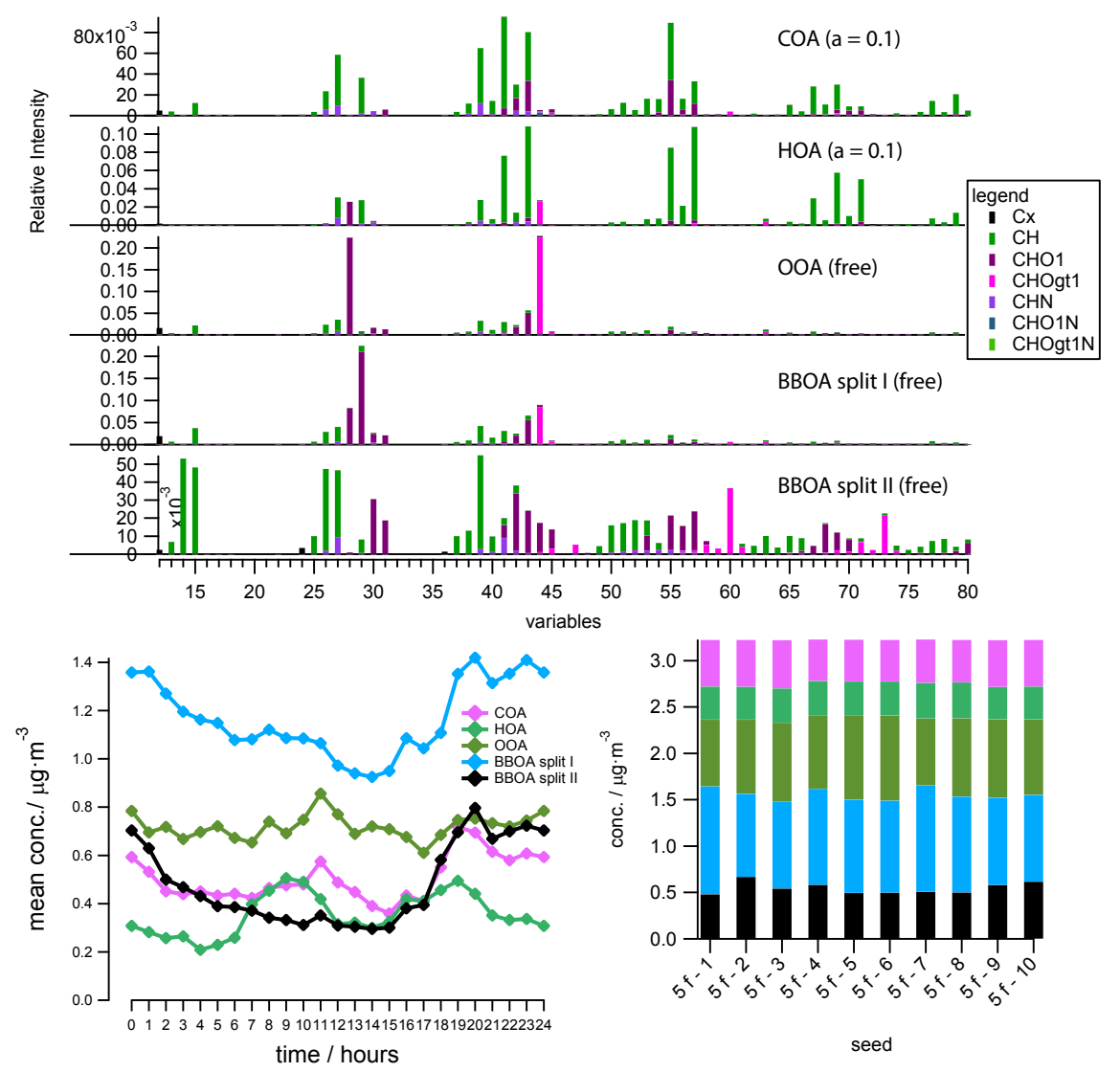

Fig. S 26. Bottom right: factor contributions of 10 seeds, 5 factor constrained PMF (ME-2). Bottom left: diurnal cycles of the 5 constrained factors. Top panel: profile of a 5 factor constrained PMF (ME-2) solution. Profile names and $a$ values are given in the plot. 


\subsection{Residuals}

The total residuals over time are shown in Fig. S27 for the 4, 5 and 8 factor unconstrained solutions and for the 4 factor constrained solution. Only little remaining variability can be observed. Also the increase to 8 factors did not significantly change the overall residual structure which indicates that already 4 factors do a "good job" explaining the variability of the dataset.

A more detailed look into the residuals of specific fragments $\left(\mathrm{C}_{3} \mathrm{H}_{3} \mathrm{O}^{+}, \mathrm{C}_{4} \mathrm{H}_{9}^{+}\right.$and $\left.\mathrm{C}_{4} \mathrm{H}_{7}^{+}\right)$is presented in Fig. S28. The $\mathrm{C}_{3} \mathrm{H}_{3} \mathrm{O}^{+}$fragment is typical for cooking related $\mathrm{OA}$ emissions while the $\mathrm{C}_{4} \mathrm{H}_{9}^{+}$fragment usually is more pronounced in HOA profiles. $\mathrm{C}_{4} \mathrm{H}_{7}^{+}$is found in both profiles to larger amounts.

The median diurnal cycles of the 4 factor unconstrained (red), the 8 factor unconstrained (green) and the 4 factor constrained solution using the HOA and COA profiles found in the $8 \mathrm{~F}$ solution are shown. $\mathrm{C}_{3} \mathrm{H}_{3} \mathrm{O}^{+}$clearly shows increased residuals during mealtimes (11 a.m. to 2 p.m. and 7-8 p.m.) while $\mathrm{C}_{4} \mathrm{H}_{9}^{+}$shows increased residuals during the traffic rush hour times ( 7 a.m. and 5 p.m.). $\mathrm{C}_{4} \mathrm{H}_{7}^{+}$does not show any clear peaks. An increase to 8 factors decreases the median residual of $\mathrm{C}_{3} \mathrm{H}_{3} \mathrm{O}^{+}$significantly during mealtimes (e.g. by $59 \%$ at 1 p.m.) and the median residuals of $\mathrm{C}_{4} \mathrm{H}_{9}^{+}$during rush hours (e.g. by $52 \%$ at 7 a.m.) while $\mathrm{C}_{4} \mathrm{H}_{7}^{+}$, which is important for both COA and HOA does not show large differences. By constraining the extracted profiles, the residuals increase again a bit but still are significantly lower than in the unconstrained case with the same number of factors (difference $\mathrm{C}_{3} \mathrm{H}_{3} \mathrm{O}^{+}: 32 \%$, difference $\mathrm{C}_{4} \mathrm{H}_{9}^{+}: 37 \%$ ). This behaviour of the residuals strongly points towards a previously mixed factor which explained well the variation of the shared signals (e.g. $\mathrm{C}_{4} \mathrm{H}_{7}^{+}$) but not taking into account the differences at the more typical fragments of $\mathrm{COA}$ and $\mathrm{HOA}$ $\left(\mathrm{C}_{3} \mathrm{H}_{3} \mathrm{O}^{+}\right.$and $\left.\mathrm{C}_{4} \mathrm{H}_{9}^{+}\right)$. Consequently, extracting and constraining COA and HOA helped to better separate these OA sources. 

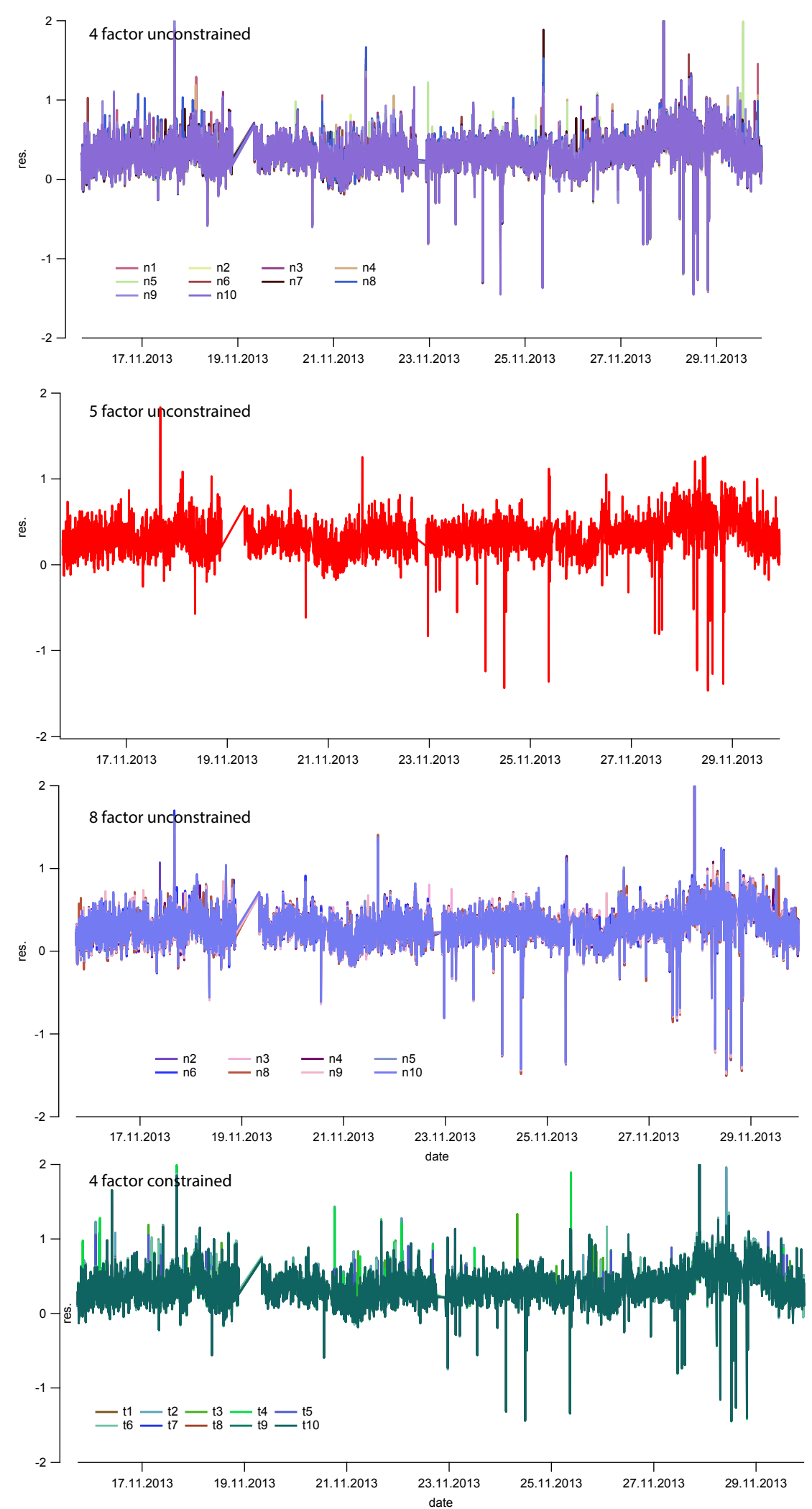

Fig. S 27. Total residual time series during the whole period for (from top to bottom): 4 factor unconstrained, 5 factor unconstrained, 8 factor unconstrained, 4 factor constrained PMF. Different colours in a plot mean different seeds. 

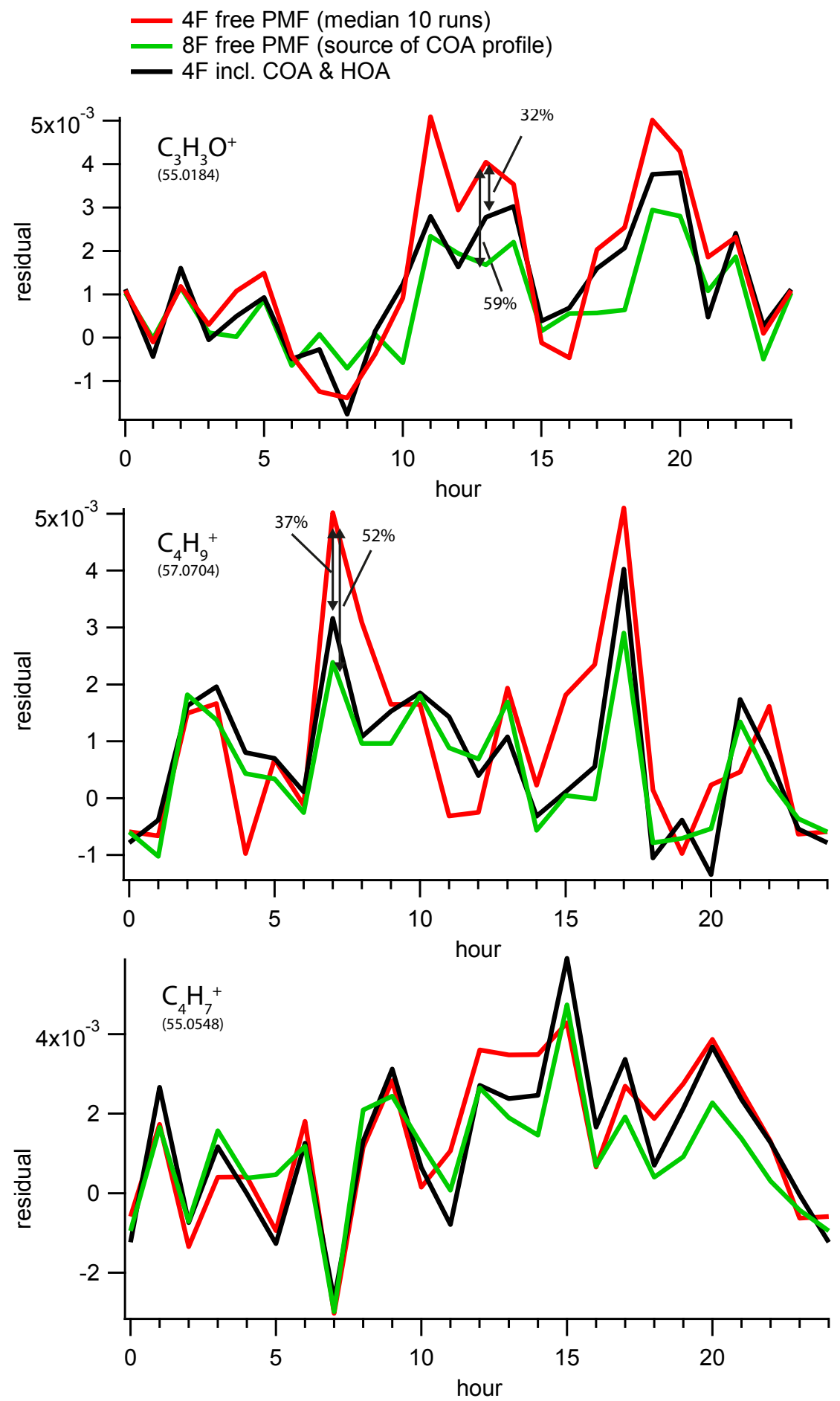

Fig. S 28. Diurnal cycle of residuals of specific fragments (from top to bottom): $\mathrm{C}_{3} \mathrm{H}_{3} \mathrm{O}^{+}, \mathrm{C}_{4} \mathrm{H}_{9}^{+}, \mathrm{C}_{4} \mathrm{H}_{7}^{+}$. The different traces show different PMF runs: 4 factor unconstrained PMF (red), 8 factor unconstrained PMF (green), 4 factor constrained PMF/ME-2 (black). 


\section{ACSM PMF analysis diagnostics}

The variability of 10 seed runs for each ACSM is shown in Fig. S29. The appearance of two groups of solutions: type I (similar to "t 8 ") and type II (similar to "t3") which was already discussed in Sect. 3.4 of the Supplementary also was observed in all ACSM except \#1. The frequency of type II which exhibits the better correlations with external data seems to decrease with instrument number and hence total f44. The solutions of type II are shown in full colours and type I solutions in light colours. Within the type II which were considered in the final results discussed in the manuscript only little variation is observed within an instrument. 

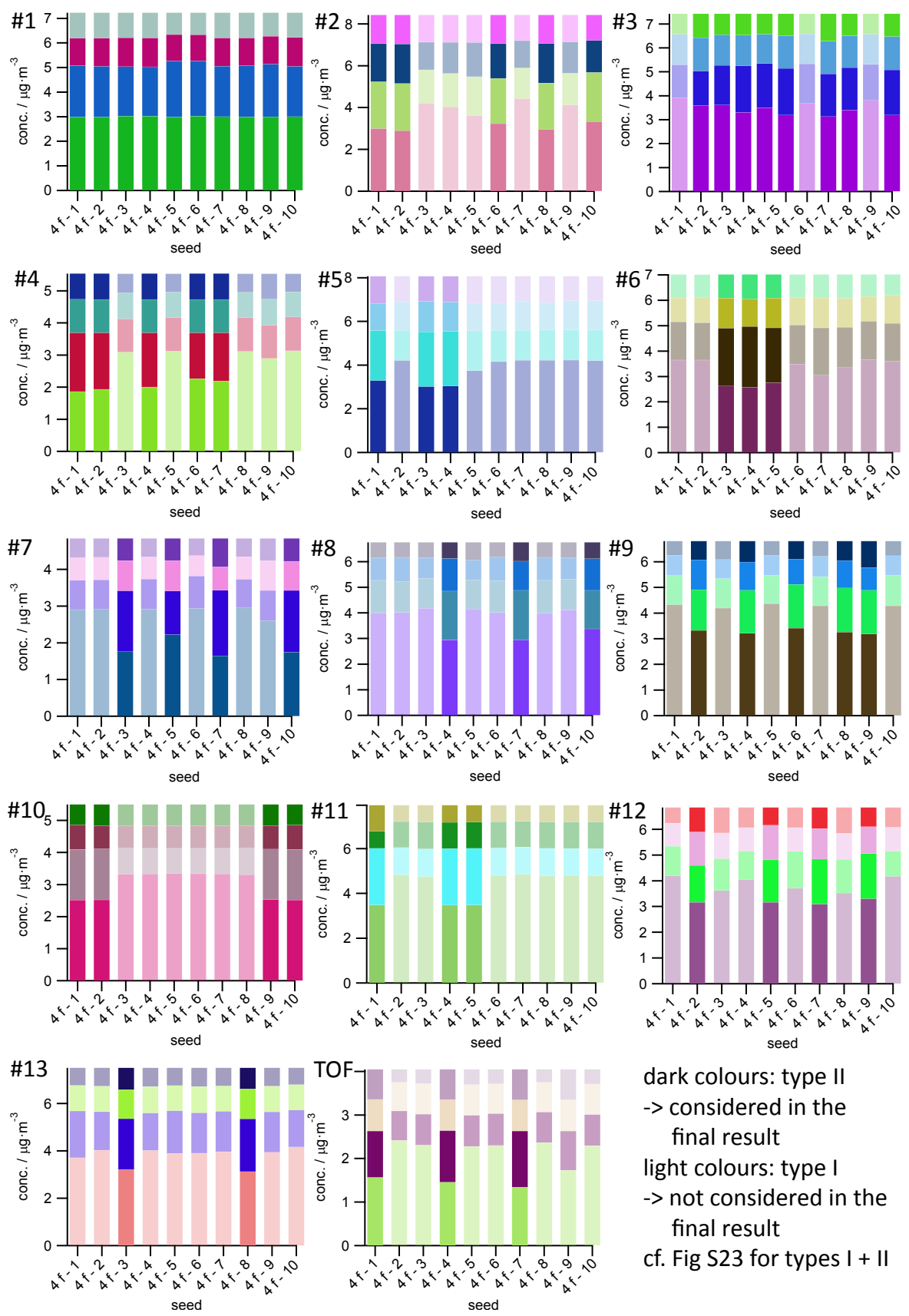

dark colours: type II $\rightarrow$ considered in the final result light colours: type I $\rightarrow$ not considered in the final result cf. Fig S23 for types I + II

Fig. S 29. Factor contributions of 10 seeds for ACSM \# 1 to \# 13 and for the ToF-ACSM. Solutions are separated into type I and type II, cf. Sects 3.4 and 4 of the Supplementary. 


\section{References}

Crenn, V., Sciare, J., Croteau, P. L., Favez, O., Verlhac, S., Belis, C. A., Fröhlich, R., Aas, W., Äijälä, M., Alastuey, A., Artiñano, B., Baisnée, D., Baltensperger, U., Bonnaire, N., Bressi, M., Canagaratna, M., Canonaco, F., Carbone, C., Cavalli, F., Coz, E., Cubison, M. J., Gietl, J. K., Green, D. C., Heikkinen, L., Lunder, C., Minguillón, M. C., Močnik, G., O’Dowd, C. D., Ovadnevaite, J., Petit, J.-E., Petralia, E., Poulain, L., Prévôt, A. S. H., Priestman, M., Riffault, V., Ripoll, A., Sarda-Estève, R., Slowik, J., Setyan, A., and Jayne, J. T.: ACTRIS ACSM Intercomparison: part I - Intercomparison of concentration and fragment results from 13 individual co-located aerosol chemical speciation monitors (ACSM), submitted to Atmos. Meas. Tech. Disc., 2015.

Crippa, M., DeCarlo, P. F., Slowik, J. G., Mohr, C., Heringa, M. F., Chirico, R., Poulain, L., Freutel, F., Sciare, J., Cozic, J., Di Marco, C. F., Elsasser, M., Nicolas, J. B., Marchand, N., Abidi, E., Wiedensohler, A., Drewnick, F., Schneider, J., Borrmann, S., Nemitz, E., Zimmermann, R., Jaffrezo, J.-L., Prévôt, A. S. H., and Baltensperger, U.: Wintertime aerosol chemical composition and source apportionment of the organic fraction in the metropolitan area of Paris, Atmos. Chem. Phys., 13, 961981, 2013.

Daellenbach, K. R., Bozzetti, C., Křepelová, A., Canonaco, F., Wolf, R., Huang, R.-J., Zotter, P., Crippa, M., Slowik, J. G., Zhang, Y., Szidat, S., Baltensperger, U., Prévôt, A. S. H., and El Haddad, I.: Characterization and source apportionment of organic aerosol using offline aerosol mass spectrometry, in prep. Atmos. Meas. Tech., 2014.

ISO13528: Statistical methods for use in proficiency testing by interlaboratory comparisons, ISO 13528, International Organization for Standardization, Geneva, Switzerland, 2005. 